\title{
NUMERICAL ANALYSIS OF THE IN-PLANE BEHAVIOUR OF THREE-LEAF STONE MASONRY PANELS CONSOLIDATED WITH GROUT INJECTION
}

\author{
Bruno Silva (Corresponding author) \\ (E-mail: bruno.silva@dicea.unipd.it; Phone: 00351225081887; Fax: 00351225081446) \\ Department of Civil Engineering - FEUP, University of Porto, Portugal \\ Rua Dr. Roberto Frias s/n, 4200-465 Porto, Portugal.
}

\author{
Athanasios Pappas \\ (E-mail: athanasios.pappas@ dicea.unipd.it; Phone: 00390498275560; Fax: 00390498275631) \\ Department of Civil, Environmental and Architectural Engineering, University of Padova, Italy \\ Via Marzolo, 9 - 35131 Padova, Italia.
}

\section{João Miranda Guedes}

(E-mail: jguedes@fe.up.pt; Phone: 00351225081887; Fax: 00351225081446)

Department of Civil Engineering - FEUP, University of Porto, Portugal

Rua Dr. Roberto Frias s/n, 4200-465 Porto, Portugal.

\section{Francesca da Porto}

(E-mail: francesca.daporto@unipd.it; Phone: 00390498275631; Fax: 00390498275631)

Department of Civil, Environmental and Architectural Engineering, University of Padova, Italy

Via Marzolo, 9 - 35131 Padova, Italia.

\section{Claudio Modena}

(E-mail: claudio.modena@ unipd.it; Phone: 00390498275613; Fax: 00390498275613)

Department of Civil, Environmental and Architectural Engineering, University of Padova, Italy Via Marzolo, 9 - 35131 Padova, Italia.

\footnotetext{
Abstract: This paper presents the calibration procedures of a numerical model based on the results of uniaxial and shear-compression tests on three-leaf stone masonry panels in scale 1:1 and 2:3, both in original and injected conditions. The stone masonry panels were simulated considering a macro-scale approach, where a nonlinear continuum damage model with distinct scalar damage parameters for tension and compression, implemented in the finite element software Cast3M, was used to simulate the walls behaviour.

The main goal of this paper is, first to calibrate, based on the obtained experimental results and using a phenomenological calibration strategy, a single set of parameters that represent a macroscopic constitutive law, by type of masonry, which is able to describe the different experimental tests. Afterwards, a parametric study
} 
was performed using the calibrated material laws, with the scope of assessing the influence of vertical precompression, slenderness and material strength on failure mechanisms and on different performance parameters such as the maximum load and displacement capacity (drift at ultimate state and drift at maximum load), for each type of masonry condition.

Keywords: Stone masonry; Grout injection; compression tests; shear-compression tests; parametric analyses; damage model; FEM. 
Stone masonry is one of the oldest structural materials. It has been widely used, mainly up to the middle of the $\mathrm{XX}^{\text {th }}$ century, on a large variety of constructions, either common or monumental, some of them being today classified as local, national, or even world cultural heritage.

Stone masonry is by nature a heterogeneous material; its components present a quite unknown geometry and a high mechanical variability, which makes the analysis of its mechanical behaviour quite complex. The structural behaviour of stone masonry elements depends on the physical, chemical and mechanical characteristics of the masonry components, but also on the way they are put together, i.e. on the masonry texture and the element's cross-section. As so, it is of great interest the development and calibration of effective modelling and analysis strategies capable of predicting the behaviour of stone masonry structures, in particular under cyclic loads. For this, it is necessary to accurately characterize this type of material through experimental testing. However, achieving a good characterization of masonry structures, detailed enough to be used on the simulation is, most of the time, a very demanding task, both in terms of cost and time.

Different approaches are available for the simulation of masonry, being the most common limit analysis, Finite Element Methods (FEM) and Discrete Element Methods (DEM). Each of these approaches present clear advantages and limitations when applied to masonry, which are mainly related to their representativeness, computer efficiency, data availability and applicability, (Roca et al. 2010). Among these, FEM is one of the most used approaches for modelling. It offers a large variety of possibilities to carry out non-linear analysis of masonry structures, from micro-modelling to macro-modelling, according to the different detailing options adopted to represent the material discontinuities and heterogeneities.

Some authors, such as (Costa et al. 2010) use a detailed micro-modelling approach, reducing masonry to its basic components, (joints, blocks and infill). In this detailed micro-model, units and mortar are described using continuum finite elements; whereas the unit-mortar interface is represented by discontinuous elements that can crack or slip.

The primary aim of micro-modelling approaches is to represent masonry on the basis of constituent materials and interface properties. The necessary data is obtained from laboratory tests on materials and small masonry samples. Nevertheless, the high level of refinement of micro-models means an intensive computational effort, which limits their applicability to the analysis of small elements (e.g. laboratory specimens) or small portions of a structure. This drawback is partially overcome by simplified micro-models. Some authors (Lourenço 1996; Lourenço and Rots 1997; Lagomarsino and Gambarotta, 1997) opted for simplified strategies characterized by the combination, or omission, of certain constituents, drastically reducing the computation time without a great loss of accuracy.

The macro-modelling approaches use homogeneous or continuous mechanical models, taking into account all elements of an assembly of materials without making distinction between the units and joints behaviour. This type of approach regards masonry as a fictitious homogeneous material by considering an appropriate relationship established between average masonry stresses and strains, which may be obtained by adopting 
phenomenological approaches, or using homogenization techniques. Due to the complex nature of heterogeneous quasi-brittle materials, such as masonry, in which the evolution of macroscopic properties is highly influenced by the complex micro-structural behaviour, some authors pursued multiscale continuousdiscontinuous computational homogenization modelling strategies that reflect the interplay between the different length scales in the damaging process (Nguyen et al. 2011; Massart et al. 2007), as an alternative to the formulation of complex closed-form macroscopic constitutive laws, which often require strong assumptions. Authors such as (De Bellis and Addessi 2011) developed research on computational homogenization using a Cosserat continuum, while authors such as (Badillo 2012) and more recently (Petracca et al. 2015) worked on approaches based on first order computational homogenization and regularization procedure, based on the fracture energy of the micro-scale-constituents.

Macro-modelling is probably the most common approach due to its smaller calculation demands. In practiceoriented analyses on large structural members, or full structures, macro-modelling is still accurate enough to characterize the structural response, in particular when plasticity or damage constitutive laws are considered, to allow the models to account for material degradation. When considering Continuum Damage Finite Element Models, isotropic criteria are usually preferred due to their mathematical simplicity and the need for only few material parameters.

The smeared crack scalar damage models, such as those presented in (Faria 1994; Cervera 2003), are often used for macro-modelling of masonry. In this type of models, damage in a given point is expressed by a scalar value that defines the level of material degradation, ranging from elastic to collapse, and cracking is considered as distributed along a certain surface, or volume. Those smeared crack scalar damage models are commonly used for analysis of reinforced concrete structures (Faria et al. 2004), or large volumes of concrete (Faria 1994). This model was later updated by several authors to be used for masonry; in (Berto et al. 2002) it was developed a specific damage model for orthotropic brittle materials with different elastic and inelastic properties along the two material directions; in (Cervera et al. 2010) the smeared-crack scalar damage model was modified to reproduce localized individual (discrete) cracks, being later enhanced by (Pelà et al. 2013) to account for the masonry's orthotropic behaviour. In reality, macro-models have been extensively used to analyse the seismic response of different types of complex masonry structures (Roca et al. 2004; Pelà et al. 2009; Silva et al. 2010); some results have been also compared to their actual observed damage state (Endo et al. 2015; da Porto et al. 2012).

Notice that macro-models present significant limitations to simulate strong discontinuities between different blocks, or parts of the masonry construction that are not easily describable by means of a FEM approach strictly based on continuum mechanics. However, this modelling strategy becomes suitable when factors such as time, simplicity and computational capacity are crucial. It is oriented for the everyday use in the analysis of real structures and when there is the need of maintaining a good balance between accuracy and computational time. With this in mind, and also considering future applications to large-scale structures, this study adopts a macromodelling strategy, considering a continuum finite-element model with distinct scalar damage parameters for tension and compression (Faria and Oliver 1993) to simulate an experimental research on three-leaf load- 
bearing stone masonry panels in scale 1:1 and 2:3, both in original and strengthened with grout injection states (Silva et al. 2014a; Silva et al. 2014b). The main objective of this experimental campaign was to assess the effectiveness of grout injection as a strengthening technique and to shed light on its influence on the mechanical behaviour of stone masonry elements, by means of uniaxial and shear-compression tests.

Therefore, first this paper calibrates, based on the obtained experimental results and using a phenomenological calibration strategy, a single set of parameters that represent a macroscopic constitutive law, by type of masonry, able to describe the different experimental tests. Afterwards, a set of parametrical analyses allows assessing the influence of the vertical pre-compression level and the specimens slenderness on the specimens performance, namely on the maximum horizontal load $\left(\mathrm{H}_{\max }\right)$, displacement capacity (drift at ultimate state - $\psi_{\delta u}$ - and drift at maximum load $\left.-\psi_{\mathrm{H} \max }\right)$ and failure mechanisms, for each type of masonry condition. In other words, this study allows predicting the performance parameters of the tested masonry for different in-situ conditions, without having to resort to further experimental tests. Finally, the results also allow drawing conclusions about the adopted experimental procedures, the behaviour of the tested masonry typology and the reliability of the modelling strategy to simulate these structural elements and to carry out parametric analyses.

\section{Experimental work}

\subsection{Experimental campaign}

An experimental campaign was performed at the Laboratory of Building Materials of the Department of Civil, Environmental and Architectural Engineering of the University of Padova on three-leaf (3L) stone masonry panels in full scale 1:1 (F) and reduced scale 2:3 (S), in original (NI) and consolidated conditions using grout injection (I), i.e. with the following references: $3 \mathrm{LF}_{\mathrm{NI}}, 3 \mathrm{LF}_{\mathrm{I}}, 3 \mathrm{LS}_{\mathrm{NI}}$ and $3 \mathrm{LS}_{\mathrm{I}}$ (Silva 2012; Silva et al. 2014a; Silva et al. 2014b). The specimens were built to reproduce the typical stone masonry of minor historical buildings.

The specimens were composed of two external leaves, each about $18 \mathrm{~cm}(1: 1 \mathrm{scale})$ or $12 \mathrm{~cm}(2: 3$ reduced scale) thick. The stones consisted of rough-shaped limestone blocks no more than about $25 \mathrm{~cm}$ long, arranged in subhorizontal courses with mortar joint thicknesses varying from $1-7 \mathrm{~cm}(1: 1 \mathrm{scale})$ and $1-4 \mathrm{~cm}(2: 3 \mathrm{scale})$. The internal core, about $14 \mathrm{~cm}(1: 1)$ and $9 \mathrm{~cm}(2: 3)$ thick, was made with limestone fragments poured into noncompacted layers between the two external leaves. This type of masonry is characterised by many voids in the inner leaf. The panels had a percentage of voids and a thickness ratio so that the grout injection was efficient, but still being representative of real walls. The walls were constructed without any type of transversal connection between the leaves, i.e. considered the most unfavourable situation.

Three types of calcareous stone (red stone, regular white stone and irregular white stone) were taken from the Cugnano quarry in Belluno, in the north-east of Italy. The lime mortar (T30V) was composed of a binder of natural hydraulic lime and lime putty (ratio 1:3), with a lime to sand ratio of $1: 3$ and a water to binder ratio of 0.35 . 
Half of the three-leaf panels were strengthened by injecting a natural hydraulic lime grout, a special, highfluidity mix with an exclusive base of Fenix NHL5, sulphate-resistant with a low water-soluble salt content, designed for consolidating stone masonry structures. Injections were carried out after mortar curing. To optimise the distribution of injection holes and, consequently, of the injected grout, a triangular mesh of equilateral triangles with $30 \mathrm{~cm}$ sides was drawn, allowing a dense distribution of the holes. Injections were carried out by one side only; on the opposite side, control holes were drilled on a mesh with $60 \mathrm{~cm}$ sides.

Monotonic and cyclic uniaxial compression tests and shear-compression tests were carried out on original and injected panels. These tests were complemented by mechanical, physical and chemical characterization of the used materials (stone, mortar and grout) and of composite elements of stone fragments and grout, in both scales 1:1 and 2:3, simulating the internal core of masonry (Silva 2012; Silva et al. 2014a).

\subsection{Experimental results}

\subsubsection{Uniaxial compression tests}

The uniaxial compression tests (Silva et al. 2014a) were carried out on 12 three-leaf specimens under different conditions (original and injected) and different scales (full scale 1:1-100mm of width x 120mm of height $\mathrm{x}$ $50 \mathrm{~mm}$ thick - and reduced scale 2:3 - 80mm of width x 100mm of height x 33mm thick), using monotonic and cyclic loads, Table 1. The specimens were subjected to uniaxial stress state to evaluate the maximum compressive strength, $\sigma_{\max }$, and the post-peak behaviour.

The specimens were instrumented with linear potentiometric displacement transducers of four different ranges $( \pm 5.0 \mathrm{~mm}, \pm 12.5 \mathrm{~mm}, \pm 25.0 \mathrm{~mm}$ and $\pm 50.0 \mathrm{~mm})$ to estimate the vertical, horizontal and transversal deformations of the panels, Fig. 1.

The experimental tests under uniaxial compression (Silva et al. 2014a) allowed concluding that:

- After consolidation, the average compressive strength and elastic modulus of all specimens approximately doubled.

- Although injected panels had higher deformability at $\sigma_{\max }$, cracks and strains started to increase at stress levels higher than those of non-injected panels. Grout injection is thus mechanically compatible with the original panels and, at the same time, improves wall performance by delaying leaf separation.

- When comparing the experimental results with literature values, the values and respective increments after consolidation of the determined mechanical characteristics show good matches, particularly as regards compressive strength, elastic modulus and vertical deformation.

- The average elastic modulus and compressive strength values and respective increments after consolidation of scale 1:1 and 2:3 specimens are approximately the same. This is of great importance for future research, as scaled specimens may be used for evaluating the effectiveness of grout injection with uni-axial compression tests. 
Table 1 shows the main results of uniaxial compression tests: maximum compressive strength $\left(\sigma_{\max }\right)$, stress at first cracking $\left(f_{1, \text { cr }}\right)$, the ratio of these two values and elastic modulus between $10 \%$ and $40 \%$ of $\sigma_{\max }\left(\mathrm{E}_{10 \%-40 \%}\right)$. Detailed descriptions of cyclic tests results are reported in (Silva 2012; Silva et al. 2014a; 2014c).

\subsubsection{Shear-Compression tests}

Shear compression tests (Silva et al. 2014b) were performed on 16 three-leaf panels in various conditions (original and injected), scales (full scale 1:1 and reduced scale 2:3 - same dimensions as the panels under compression tests) and under different pre-compression levels. The specimens were tested with cantilever-type boundary conditions. Pre-compression levels of $0.5,0.75,1.0$ and $1.25 \mathrm{~N} / \mathrm{mm}^{2}$ were considered for the original specimens and of $1.0,1.25,1.5$ and $2.0 \mathrm{~N} / \mathrm{mm}^{2}$ for the injected specimens, for both scales $1: 1$ and 2:3. These levels were selected to obtain the most typical failure modes: shear, flexural and mixed.

After applying the vertical load (V), cyclic tests were carried out under displacement control, by applying horizontal displacement $(\delta)$ histories with increasing amplitudes and peaks. The vertical force was maintained constant during each test and each displacement peak was repeated three times. All tests were carried out up to the specimens collapse, i.e. until a null value of lateral resistance was achieved, allowing the post-peak phase to be assessed. Fig. 2 shows the monitoring scheme used for the various types of specimen.

The most relevant conclusions of this experimental campaign were that:

- The more highly pre-compressed specimens achieved greater maximum resistance with more brittle failure at the final phase.

- Original panels subjected to higher vertical loads exhibited mainly shear mechanisms, whereas lower pre-compressed specimens developed a flexural mechanism. Injected panels were influenced by rocking mechanisms at the base.

- The first crack appeared on injected panels at almost double displacements than on original panels. At maximum resistance, injected panels exhibited 3 times higher displacements for almost 2 times higher forces than the original panels. A rapid decrease in stiffness in all specimens subjected to lower precompression was observed. Injected panels clearly had higher starting stiffness compared to original panels, and a more rapid decrease due to rocking.

- The analysis of the mechanical properties revealed that, after grout injection, the tensile strength $f_{t}$ increased 3 times and the shear modulus $\left(G_{\text {exp }}\right)$, estimated experimentally, increased approximately 4.0 times.

- The change of the scale factor changed the influence of pre-compression on the panels behaviour. The same collapse mechanisms for the same pre-compression values could not be reproduced in both 1:1 and 2:3 scale panels. However, in general, the use of scaled specimens may be considered representative of the type of masonry tested here.

During the in-plane shear cyclic tests the specimens exhibited different overall behaviour, depending on the condition of the specimens (original/injected), the scale of the panel and the applied vertical load. Four different 
phases/limit states, which can be used to simplify and idealise the behaviour of the masonry panels, were observed. These limit states correspond to changes on how the specimens resist the progressive increment of the applied lateral displacement, Fig. 3. Four points may be defined: (i) Flexural cracking $\left(\mathrm{H}_{\mathrm{f}}, \delta_{\mathrm{f}}\right)$, defined by the horizontal cracking of the first mortar bed joint between the specimen and the lower concrete beam/basement and/or cracking of the second mortar bed joint; (ii) Cracking Limit State $\left(\mathrm{H}_{\mathrm{cr}}, \delta_{\mathrm{cr}}\right)$, defined by the first cracking typical of the mechanism, either shear or rocking, that characterizes the specimen failure. (iii) Maximum Resistance $\left(\mathrm{H}_{\max }, \delta_{\mathrm{Hmax}}\right)$, defined by the attainment of the maximum horizontal load $\mathrm{H}_{\max }$ and the corresponding displacement $\delta_{\mathrm{Hmax}}$; (iv) Ultimate limit $\left(\mathrm{H}_{\delta \mathrm{u}}, \delta_{\mathrm{u}}\right)$, when the specimen reaches the ultimate state, i.e. the maximum displacement $\delta_{u}$, to which corresponds a value of residual lateral resistance $\mathrm{H}_{\delta \mathrm{u}}$. This type of simplified models is very useful to compare the performances of different types of masonry, in terms of initial stiffness, maximum resistance and ultimate ductility.

Fig. 4 shows an example of hysteretic cycles of two specimens, while Fig. 5 shows the idealised envelope curves of the hysteretic behaviour and the four limit states described above. Table 2 lists the strength and ductility indicators of all specimens.

\section{$3 \quad$ Numerical modelling}

\subsection{Numerical behaviour model}

The panels were modelled using a continuum damage model based on the Continuum Damage Mechanics capable of reproducing the various degrading phenomena that occur under tension or compression. In particular, the adopted model incorporates two damage variables; one for tension $\left(\mathrm{d}^{+}\right)$and another for compression $\left(\mathrm{d}^{-}\right)$and a plastic deformation tensor for the characterization of the non-linear degradation mechanisms under tensile and compression conditions (Faria and Oliver 1993).

The model reproduces the material tension / deformation curves, including hardening and softening effects and the mechanisms of stiffness recovery. The effect of damage on the material properties is reproduced in the stiffness constitutive tensor, by reducing several stiffness components. The damaged material may remain isotropic or become anisotropic.

The damage variables $\left(d^{-}\right.$and $d^{+}$) can assume values between 0 and 1 (Eq. 1); 0 corresponds to the elastic state and it increases with damage until it reaches 1 , which corresponds to collapse. This evolution is characterized by the decrease of the effective resistant area, i.e., the area without defects.

$0 \leq\left(d^{+}, d^{-}\right) \leq 1$

Eq. 1

Under the adopted constitutive model, these damage variables are associated with the material degradation produced under tension or compression, and are defined as explicit functions of scalar norms of the tensors $\bar{\sigma}^{+}$ and $\bar{\sigma}^{-}$, leading to the following constitutive law: 
As explained by Faria (1994), when applied to tensile or compression 1D tests, in which one of the components is always zero, the constitutive law presented in Eq. 2 is reduced to the scalar equations Eq. 3 and Eq. 4, according to the type of test (tensile or compression) and to the curves presented in Fig. 6.

Uniaxial tensile test:

$\sigma=\left(1-d^{+}\right) \cdot \bar{\sigma}^{+}=\left(1-d^{-}\right) \cdot E \cdot \varepsilon$

Eq. 3

Uniaxial compressive test:

$$
\sigma=\left(1-d^{-}\right) \cdot \bar{\sigma}^{-}=\left(1-d^{-}\right) \cdot E \cdot\left(\varepsilon-\varepsilon_{p}\right)
$$

To define whether the element is "loading", "unloading" or "reloading", the model adopts the concept of equivalent stress $\bar{\tau}^{+}$and $\bar{\tau}^{-}$(Eq. 5 and Eq. 6) associated to a positive scalar value, which is the result of the effective stresses tensors norm. The various three-dimensional states of stress can then be compared through a 1D analysis. Following the tensor decomposition, the equivalent tensile and compressive stresses are then associated to different damage criteria, (Eq. 7 and Eq. 8).

$$
\begin{aligned}
& \bar{\tau}^{+}=\sqrt{\bar{\sigma}^{+}: D_{0}^{-1}: \bar{\sigma}^{+}} \\
& \bar{\tau}^{-}=\sqrt{\sqrt{3}\left(K \bar{\sigma}_{\text {oct }}^{-}+\bar{\tau}_{\text {oct }}^{-}\right.}
\end{aligned}
$$

Where $\bar{\sigma}_{o c t}^{-}$and $\bar{\tau}_{\text {oct }}^{-}$are, respectively, the normal and tangential octahedral stresses extracted from the tensor $\bar{\sigma}^{-}, K$ a material property and $\mathrm{D}_{0}$ represents the usual constitutive linear elastic $4^{\text {th }}$ order matrix. Following the tensor decomposition, the equivalent tensile and compressive stresses are then associated to different damage criteria (Eq. 7 and Eq. 8).

$$
\begin{aligned}
& \bar{\tau}^{+}-r^{+} \leq 0 \\
& \bar{\tau}^{-}-r^{-} \leq 0
\end{aligned}
$$

where $r^{+}$and $r^{-}$are damage thresholds, which can also be regarded as hardening variables that control the evolution of the damaged surfaces. The initial values of the damage thresholds $r_{0}^{+}$and $r_{0}^{-}$are associated with the limits $f_{0}^{+}$and $f_{0}^{-}$which represent the linear stress tensile and compressive limits.

\section{Behaviour in tension}

The continuous damage model incorporates two different ways to represent behaviour in tension. This difference is related to the post-peak behaviour, which can is defined according to a (i) linear criteria or to an (ii) exponential criteria. In the current work an exponential softening behaviour, with zero drop factor $\left(\Delta f_{0}^{+}\right)$, was adopted to represent the tensile post peak behaviour. Under these assumptions, the tensile damage variable evolution may be defined by the following equation: 
$d^{+}=1-r_{0}^{+} / r^{+} e^{A^{+}\left(1-r^{+} / r_{0}^{+}\right)}$

, if $r^{+} \geq r_{0}^{+}$

Eq. 9

The tensile behaviour curve is based on the distributed crack mechanical principles (Bažant et al. 1983; Bažant 1986), being the descendant branch defined in function of the tensile fracture energy $(G f)$, included in parameter $A^{+}$of equation Eq. 9, which is dependent on the characteristic length $\left(l^{*}\right)$ of the finite element, as described in Eq. 10 .

$l^{*}=\sqrt{\Delta A} \quad$ (2D Domain)

$l^{*}=\sqrt[3]{\Delta V} \quad$ (3D Domain)

Eq. 10

where $(\Delta \mathrm{A}$ expresses the area and $\Delta \mathrm{V}$ the volume associated to the integration point.

\section{Behaviour in compression}

The damage variable evolution under compression is defined as presented in Eq. 11. It implies the use of 2 additional parameters $\left(A^{-}\right.$and $\left.B\right\urcorner$ ), which are defined by imposing the $\sigma-\varepsilon$ 1D numerical curve to convey two selected points $\left(\mathrm{P} 1-\varepsilon_{1}{ }^{-}, \sigma_{1}{ }^{-}\right.$and $\left.\mathrm{P} 2-\varepsilon_{2}{ }^{-}, \sigma_{2}{ }^{-}\right)$on a curve extracted from a 1D compression test. See (Faria and Oliver 1993) for further details.

$d^{-}=1-r_{0}^{-} / r^{-} .\left(1-A^{-}\right)-A^{-} \cdot e^{B^{-}\left(1-r^{-} / r_{0}^{-}\right)} \quad$, if $r^{-} \geq r_{0}^{-}$

When plastic strains are envisaged the evolution of the plastic strain tensor may be expressed as follows:

$\dot{\mathcal{\varepsilon}}^{p}=\beta E H\left(\dot{d}^{-}\right) \frac{\langle\bar{\sigma}: \dot{\varepsilon}\rangle}{\bar{\sigma}: \bar{\sigma}} D_{0}^{-1}: \bar{\sigma}$

where the Heaviside function $H\left(\dot{d}^{-}\right)$introduces a dependence of the plasticity kinematics with regards to the evolution of the damage variable in compression. This dependence allows cancelling the evolution of the plastic deformations during the unloading steps, or before reaching the compression damage threshold $r_{0}^{-}$.

As for parameter $\beta$, it is used to calculate the residual plastic strains and, consequently, the cyclic unloading and reloading stiffness and energy dissipation in compression. Parameter $\beta$ depends on the reference plastic strain $\left(\varepsilon^{p}\right)$ and stress $\left(\sigma^{p}\right)$, on the elastic modulus $(E)$ and on the peak $\left(f_{u}^{-}\right)$and elastic limit stresses $\left(f_{0}^{-}\right)$, according to the following equation:

$\beta=\frac{\left(E \varepsilon^{p-}-\sigma^{p-}\right) f_{u}^{-}}{\left(E \varepsilon^{p-}-f_{0}^{-}\right)\left(\sigma^{p}+f_{u}^{-}\right)}$

Initially developed and implemented by Faria in a standalone program (Faria and Oliver 1993), the model is also available in CAST3M software (Pasquet 2003; Costa et al. 2005) and is defined by the parameters presented in Table 5 .

\subsection{Calibration of the behaviour model}


The calibration process consisted in fitting the behaviour model parameters to the experimental results of the uniaxial compression and shear-compression tests on three-leaf stone masonry panels (Silva 2012; Silva et al. 2014a; 2014b; 2014c). The first calibration was performed at the material level, based on the results of the uniaxial compression tests, which enabled to represent masonry as an equivalent homogeneous continuum material. The calibrated numerical model was then used to simulate the shear-compression tests. At this point, a phenomenological recalibration of the homogenous behaviour model was required, in order to render it representative of the experimental results. The parameters required by the numerical model that were not obtained experimentally were taken from the bibliography.

\subsubsection{Uniaxial compression tests}

The calibration of the model based on the experimental compression behaviour was obtained by simulating a test on a 4-node finite element of unitary dimensions under monotonic and cyclic displacement laws. It was considered that the simulated specimen was composed of a homogeneous isotropic material.

The calibration was based on the results of the compression tests carried out on the 3LF and 3LS panels under injected and original conditions, (Silva 2012; Silva et al. 2014a). The objective was to fit the numerical 1D stress-strain response to the uniaxial compression experimental results through series of uni- and multiparametric analyses. A different set of properties was used for each of the four masonry typologies: $3 \mathrm{LF}_{\mathrm{NI}}, 3 \mathrm{LF}_{\mathrm{I}}$, $3 \mathrm{LS}_{\mathrm{NI}}$ and $3 \mathrm{LS}_{\mathrm{I}}$.

The majority of the parameters were taken from the experimental results. The Poisson ratios (v), the compressive peak stresses $\left(\mathrm{f}_{\mathrm{u}}^{-}\right)$, the ultimate strains $\left(\varepsilon_{\mathrm{u}}{ }^{-}\right)$, the elastic modulus $(\mathrm{E})$ and the elastic limit stresses $\left(\mathrm{f}_{0}{ }^{-}\right.$ ) were obtained from the stress-strain diagrams. The density ( $\rho$ ) was obtained experimentally and was equal to $2200 \mathrm{~kg} / \mathrm{m}^{3}$ for the original panels and $2500 \mathrm{~kg} / \mathrm{m}^{3}$ for the injected ones.

Extensive sensitivity analyses were carried out considering different combinations of the two fitting points, P1 $\left(\varepsilon_{1}^{-}, \sigma_{1}^{-}\right)$and P2 $\left(\varepsilon_{2}^{-}, \sigma_{2}^{-}\right)$, until a good fit to the experimental results was achieved. For the equi-biaxial compressive ratio $\left(\mathrm{f}_{0,2 \mathrm{D}}{ }^{-} / \mathrm{f}_{0,1 \mathrm{D}}{ }^{-}\right)$a value of 1 was adopted.

The calibrated continuum damage model could reproduce fairly well the monotonic compression curves, in particular first cracking, maximum strength and deformation along the loading directions for both the monotonic and the cyclic tests. These parameters were further calibrated taking in consideration the cyclic compression tests. In this case, the loading and reloading behaviour had also to be simulated. As stone masonry is a very inhomogeneous material; it behaves with high plastic strains during the unloading and reloading cycles, which is controlled, in the model, by parameter $\beta$.

This behaviour could not be accurately reproduced using the experimental values. To do so, unrealistic values would have to be adopted for the parameters that directly influence $\beta$, namely the plastic parameters $\varepsilon^{p-}$ and $\sigma^{p-}$, the elastic modulus $E$ and the elastic limit stress $f_{0}^{-}$. By assuming only experimental values, it was chosen a 
reference point along the plastic branch of the curves so that the numerical unloading and reloading stiffnesses would be as close as possible to the experimental ones.

Some results of model calibration based on the monotonic and cyclic uniaxial compression tests are shown in Fig. 7; Table 3 lists the calibrated parameters for all the cyclic compression tests.

\subsubsection{Shear-compression tests}

The shear-compression tests results were simulated using the non-linear continuum damage model previously described. As starting point to the simulation of the structural analysis of the panels under shear compression, the properties adopted to define the compressive branch of the behaviour model were those calibrated for the cyclic uniaxial compression tests, see Table 3. To define the tensile branch, it were chosen parameters that give a fragile low resistant behaviour to the stone masonry, see Table 4 . The tensile strength $\left(f_{t}^{+}\right)$of the various types of masonry was taken from the shear-compression tests results. The tensile fracture energy $\left(G_{f}\right)$ was based on bibliographic research. According to Lourenço (1996), tensile fracture energy ranges between 10 and $100 \mathrm{~J} / \mathrm{m}^{2}$; an average value of $50 \mathrm{~J} / \mathrm{m}^{2}$ was selected.

The reinforced concrete top and basement beams were simulated with a strength significantly higher than that of the masonry, since they were designed not to exceed the elastic domain. Hence, their behaviour was defined as linear elastic and isotropic with $\mathrm{E}=29 \mathrm{GPa}, v=0.25$ and $\rho=2500 \mathrm{~kg} / \mathrm{m}^{3}$.

A plane stress state was assumed in all models and the actual experimental boundary conditions and loading schemes were implemented, see Fig. 8a. Eight-node elements with a Gauss integration scheme were considered. In the simulation of the shear-compression tests, the translational degrees of freedom ( $\mathrm{Ux}, \mathrm{Uy}$ ) at the base of the model were constrained. The initial vertical pre-compression was applied to the nodes of the top surface of the reinforced concrete beam; the horizontal displacements were also applied on the beam, according to the real experimental procedure, Fig. $8 \mathrm{~b}$.

The values of the parameters obtained from the calibration based on the material compression tests were not satisfactory when directly applied to the simulation of the shear compression tests. This is due to the fact that the available continuum macro-models, like the one considered in the present research, still present some limitations concerning the calibration of the shear behaviour. In fact, the shear behaviour of macro-models cannot be calibrated explicitly and separately (like in micro-models) due to its implicit dependency on the model's tensile/compressive behaviour.

As so, to properly simulate the material behaviour, further calibration of the model was done by means of a phenomenological fitting of the numerical curves to the experimental ones, through a series of mono- and multiparametric analyses. However, in the case of the parameters directly related to the mechanical properties, the values were within those experimentally obtained (Silva 2012; Silva et al. 2014b). 
Material behaviour laws (in tension and compression), capable of reproducing the in-plane behaviour under the various applied pre-compression levels, were defined for each type of tested panel, Fig. 9. Table 5 lists the relevant parameters.

Table 6 presents the percentage variation of the model parameters in relation to those calibrated for the cyclic compression tests. In particular, the results show that: (i) the elastic modulus $(E)$ of the injected specimens decreased while that of the original ones increased and (ii) the elastic limit compressive stress $\left(f_{0}^{-}\right)$decreased for all the analysed wall types. Moreover, the compressive peak stress $\left(f_{u}^{-}\right)$was adjusted in order to fit all the precompression levels applied to the various masonry panels. Apart from the injected panels in scale 1:1, in all the other panels the average compressive strength increased when compared to that obtained from the cyclic compressive tests.

The plastic parameters $\left(\varepsilon^{p^{-}}\right)$and $\left(\sigma^{p-}\right)$ were defined, as already mentioned, as a point on the plastic branch of the compressive behaviour curve that gives the highest energy dissipation capacity of masonry. The fitting point $\mathrm{P}_{1}$ $\left(\varepsilon_{1}{ }^{-}, \sigma_{1}{ }^{-}\right)$was defined in order to better adjust the cracking limit state. The fitting point $\mathrm{P}_{2}\left(\varepsilon_{2}^{-}, \sigma_{2}{ }^{-}\right)$, used to simulate the shear-compression tests of all panels, was established to give higher deformation capacity to the material. This is also visible by the high percentage increase of the ultimate limit strain $\left(\varepsilon_{u}{ }^{-}\right)$obtained in all cases.

The need to increase the deformation and resistant capacity of the structural model, when compared with the values based on the material compression tests, is justified by the formation of highly damaged localized areas, which result from the combined action of compression and bending. In practice this re-calibration allowed the model to simulate the material behaviour when solicited in a different direction other than the vertical.

Fig. 10 compares the experimental and numerical behaviour of some of the tested specimens, in terms of envelope of the hysteresis loops, where $\mathrm{H}^{+}$and $\mathrm{H}^{-}$refer to the envelope horizontal force when the walls are pushed on the positive (+) and negative direction (-), respectively. The other results can be found in (Silva 2012).

In general, a good fit was achieved between the numerical and experimental results, Fig. 10 and Table 7. The calibrated model could simulate well the initial elastic stiffness and the maximum horizontal loads $\left(\mathrm{H}_{\max }\right)$. The ratio between predicted and experimental load capacity $\left(\mathrm{H}_{\max , \mathrm{n}} / \mathrm{H}_{\text {max,e }}\right.$, see Table 7$)$ is approximately 1 for all tested panel types. The model showed some limitations in capturing the displacement at maximum load $\left(\delta_{\mathrm{Hmax}}\right)$ and the ultimate displacement $\left(\delta_{\mathrm{u}}\right)$ of the injected specimens tested under the lowest pre-compression levels (1.0MPa and 1.25MPa). This can be attributed to the experimental behaviour, which was governed by rocking (e.g., see panel $\mathrm{SCF}_{1.0 \mathrm{I}}$ in Fig. 10b). However, the $\delta_{\mathrm{Hmax}, \mathrm{n}} / \delta_{\mathrm{Hmax}, \mathrm{e}}$ and $\delta_{\mathrm{u}, \mathrm{n}} / \delta_{\mathrm{u}, \mathrm{e}}$ ratios of the other injected specimens and all the original ones are approximately 1 . The model also did not simulate accurately the unload stiffness and the energy dissipation. This is mainly due to the fact that this damage model does not capture effects like joint friction related to the panels local behaviour.

The adopted macro-modelling strategy was fairly able to reproduce the damage propagation and in-plane failure mechanisms of the panels. Crack patterns were consistent with those experimentally observed, as can be seen by 
comparing Fig. 11 and Fig. 12a. However, this type of model cannot simulate the buckling of the external leaves, which is particularly relevant in the original panels (e.g., see panel SC3LF $\mathrm{LF}_{1.25 \mathrm{~N}}$, Fig. 12b).

\section{$4 \quad$ Parametric analyses}

On the basis of the defined material behaviour laws (Table 5), a parametric study was performed. This study allowed assessing the influence of vertical pre-compression level and specimen slenderness on different performance parameters, such as the maximum horizontal load $\left(\mathrm{H}_{\max }\right)$, displacement capacity (drift at ultimate state $-\psi_{\delta u}-$ and drift at maximum load $\left.-\psi_{\mathrm{Hmax}}\right)$ and on the failure mechanisms for each type of masonry condition.

Ten vertical pre-compression levels $\left(\sigma_{0}^{\prime}\right)$ were considered: $10 \%, 20 \%, 30 \%, 40 \%, 50 \%, 60 \%, 70 \%, 80 \%$ and $90 \%$ of the maximum compressive strength. The parametric analyses were carried out on panels of six slenderness ratios $(\mathrm{sl}=\mathrm{h} / \mathrm{l}): 0.5,0.75,1.0,1.2,1.5$ and 2.0 in the case of walls in scale $1: 1$ and $0.5,0.8,1.0,1.25$, 1.55 and 2.0 in the case of the scale $2: 3$.

These parametrical analyses allowed the creation of useful correlations, which allow defining/extrapolating performance parameters for this type of masonry, considering different in-situ conditions and without having to resort to further experimental tests.

\subsection{Maximum resistance}

Fig. 13 presents the variation of the nominal average shear stress at maximum resistance (horizontal load divided by the horizontal cross sectional area) for the various pre-compression levels and slenderness, for each type of panel. The various curves in each diagram represent a specific slenderness; the hollow squares represent the experimental results.

The numerical analyses allowed identifying the dominant failure modes. This becomes evident by overlapping the numerical results to the domains associated to shear, compression and flexural failure mechanisms. The failure fields were defined on the basis of the analytical expressions presented in equations Eq. 14 to Eq. 16: 


$$
\tau_{H \max }=\frac{f_{t}}{b} \sqrt{1+\frac{\sigma_{0}^{\prime}}{f_{t}}}
$$$$
\tau=\left(1-\frac{\sigma_{0}^{\prime}}{\sigma_{\max }}\right) \cdot \frac{\sigma_{\max }}{\frac{6 . h}{l}}
$$

$\tau=\left[\frac{\sigma_{0}^{\prime}}{\sigma_{\max }}-\left(\frac{\sigma_{0}^{\prime}}{\sigma_{\max }}\right)^{2}\right] \cdot \frac{\sigma_{\max }}{\frac{2 . h}{l}}$

Flexural Failure Mechanism

Eq. 16 be defined as follows:

$$
b=\frac{h}{l}\left\{\begin{array}{l}
\geq 1 \\
\leq 1.5
\end{array} \quad-b=\left\{\begin{array}{l}
1 \text { if } \frac{h}{l} \leq 1 \\
1.5 \text { if } \frac{h}{l} \geq 1.5
\end{array}\right.\right.
$$

where $h$ and $l$ are height and length of the masonry wall, as proposed in (Benedetti and Tomaževic 1984) and as also found in recent codes (NTC 2008); $\tau_{\mathrm{Hmax}}$ is the nominal average shear stress at maximum resistance, as proposed in (Bernardini et al. 1982), were $f_{t}$ is the average values of the tensile strength presented in Table 4 and obtained from the experimental work.

These equations, such as the shear strength formulation proposed by Turnsek and Cacovic (1971), then refined by Turnsek and Sheppard (1980), were normally applied for the strength prediction of brick masonry and were also calibrated for stone masonry.

In general, a good agreement was found between the experimental data and both numerical and analytical formulations. The full scale original specimens only presented some scattered experimental values, whereas a very good response was obtained in the case of the injected panels for both scales and slenderness higher than 1 , Fig. 14. Indeed, both the analytical formulations and the behaviour model used for the numerical simulations consider a homogeneous isotropic material, which explains the general good agreement between the two approaches. The comparisons between numerical parametric analysis and analytical formulations for all the various analysed types of panel can be found in (Silva, 2012).

It was also observed that, when the lower limitation for the definition of the shear distribution factor (b) in function of the slenderness (Eq. 17) is not considered, a very good agreement is found between the numerical and analytical approaches also for slenderness values lower than 1. Further experimental tests on panels with slenderness lower than 1 are necessary in order to properly define the limitations of both numerical and analytical approaches.

In general, for the various pre-compression and slenderness levels, the injection procedure increases the panel strength compared to the original panels (approximately $250 \%$ for the scale 1:1 and $210 \%$ for the scale 2:3); the value of $\mathrm{H}_{\max }$ depends on the applied pre-compression level, slenderness and failure mode as in Fig. 13. 


\subsection{Displacement capacity}

Fig. 15 shows the variation of drift at ultimate state $\left(\psi_{\delta u}\right)$, and of drift at maximum resistance $\left(\psi_{\mathrm{Hmax}}\right)$, for the various pre-compression levels and slenderness, for the 1:1 scale panels.

In both injected and original specimens, $\psi_{\delta u}$ decreases (about $20 \%$ for the injected and $25 \%$ for the original walls) with the increase of pre-compression level, for all the considered slenderness ratios. The highest percentage decrease happens for low levels of pre-compression (from 10 to $20 \% . \sigma_{\max }$ and from 20 to $30 \% . \sigma_{\max }$ ), while for the same intervals there is an increase of $\psi_{\mathrm{Hmax}}$, followed by a subsequent decrease.

In general, for the various pre-compression and slenderness levels, the panels in scale 1:1 have $\psi_{\delta \mathrm{u}}$ and $\psi_{\mathrm{Hmax}}$ approximately $110 \%$ higher than those of the original panels, while for the panels in scale $2: 3$ this average increase is of about $150 \%$.

The behaviour in terms of drift at ultimate limit state and maximum load depends on the failure mode, which in turn depends on the wall slenderness, the applied pre-compression and material strength. The variation of failure mode can be observed from the $\mathrm{H}_{\max }$ vs. $\psi_{\delta \mathrm{u}}$ curves of Fig. 16, as well as from the $\mathrm{H}_{\max }$ vs. $\psi_{\operatorname{Hmax}}$ curves of Fig. 17. The dots in these diagrams represent the performance of each numerically analysed panel in terms of the above mentioned strength and displacement values, for pre-compression levels ranging from $10 \%$ (point on the right of each curve) to $90 \%$ (point on the left of each curve) of $\sigma_{\max }$. Each curve corresponds to a different slenderness.

These curves give an idea of the type of failure and the maximum load and displacement capacity that the original and injected walls may present, for a wide range of slenderness and pre-compression loads. However, when analysing the parametric results, the error between the experimental and numerical results presented in Table 7, particularly for what concerns the displacement capacity, must be taken into account.

Panels with low slenderness $(\mathrm{sl}=0.5)$ present a more fragile behaviour, characterized by small displacements at ultimate state because of shear failure. However, for low slenderness, when high pre-compression levels are applied, failure occurs due to crushing.

For all analysed types of masonry, the behaviour becomes more ductile (high displacements at ultimate state) for higher slenderness. Panels with high slenderness $(s l=2.0)$ tend to have flexural failure. However, for high precompression values, crushing prevails, and for low pre-compression values, particularly in injected panels, rocking prevails.

Fig. 16 and Fig. 17 also show the variation of the dominant failure modes when changing the pre-compression load, which occurs, within the same slenderness, when the curves bend sharply (at about 30 to $50 \%$ of $\sigma_{\max }$ ). Before reaching these transition points, failure can be influenced by a mixed flexural/shear behaviour, as illustrated in Fig. 11 and Fig. 18a, or a mixed shear/crushing behaviour, as illustrated in Fig. 18b.

\section{Conclusions}


A material behaviour model (Faria and Oliver 1993) was calibrated through a phenomenological approach on the basis of uniaxial and shear-compression test results on three-leaf stone masonry panels in scale 1:1 and 2:3, either in original or injected conditions (Silva 2012; Silva et al. 2014a; Silva et al. 2014b). The calibrated model was used to carry out a parametric study of panels under shear-compression loads considering various levels of vertical loads and slenderness, and strengthening conditions. The main conclusions are as follows:

- The calibrated continuum damage behaviour model is fairly able to represent the material compression curves, in particular first cracking, maximum load and deformability along the loading direction. However, the model could not represent properly the cyclic unloading and reloading stiffness and, consequently, the energy dissipation in compression.

- In the simulation of the panel's structural behaviour under shear-compression tests, the behaviour model allowed a good fit to the experimental results in terms of initial elastic stiffness and maximum horizontal loads for all specimens. In terms of displacement capacity, the model could not capture the displacement at maximum load and the ultimate displacement of the injected specimens tested under the lowest pre-compression levels.

- The applied modelling strategy allowed reproducing the sequence of failure mechanisms and crack patterns experimentally observed on the shear-compression tests. However, this type of model cannot simulate buckling of the external leaves, which was significant, in particular, on the original panels.

- A parametric study was performed considering the calibrated material laws. The study allowed relating the panel type of failure and performance parameters (maximum strength and displacement capacity) under combined shear and compression to the pre-compression loads, slenderness and strength of the material.

- The correlations established through the parametrical study allow predicting the performance parameters for this type of masonry considering different in-situ conditions, without having to resort to further experimental tests.

- Future studies should be performed on the applicability of this macro scale model and calibrated properties on large scales structures. Furthermore, given the importance of the influence of the evolving micro-structure on the macroscopic properties, especially when strain localizations occur in the microstructure leading to complex dissipation mechanisms at the structural level, a comparison with the results from simulations using different models, such as those presented in the literature, should be made. 
Acknowledgments The first author would like to thank the FCT (Fundação para a Ciência e a Tecnologia - Foundation for Science and Technology) of Portugal for the grant funding - SFRH/BPD/88115/2012. This work was carried out under EU Contract FP7-ENV-2009-1-GA244123: 'New integrated knowledge-based approaches to the protection of cultural heritage from earthquake-induced risk - NIKER'. Research was also partially supported by the Reluis Project and Executive Programme of Co-operation in the Field of Science and Technology, between the governments of Italy and Japan. Thanks are due to Tassullo S.p.A. (Italy) for providing the basic materials. Specimens were built at ESEV (masonry school, Verona, Italy) and were tested at the Laboratory of Structural Material Testing, University of Padova. The authors would also like to thank engineer E. Piccoli for his work as part of the graduation thesis.

\section{References}

Badillo HA, Numerical modelling based on the multiscale homogenization theory. Application in composite materials and structures. PhD thesis, U.P.C. Barcelona, 2012.

Bažant Z, Oh B, Crack Band Theory for Fracture of Concrete. Matériaux et Constructions, 16(93), pp. 675-705, 1983.

Bažant Z, Mechanics of distributed cracking. Book N. ARM007, Reprint of Applied Mechanics Rev., 39(5), pp. 155-176, 1986.

Benedetti D, Tomaževič M, Sulla verifica sismica di costruzioni in muratura, Ingegneria Sismica, I(0), 9-16, 1984. (in Italian)

Bernardini A, Modena C, Turnšek V, Vescovi U, A comparison of laboratory test methods used to determine the shear resistance of masonry. Proc. $7^{\text {th }}$ World Conference on Earthquake Engineering, Istanbul, Turkey, 7 , 181-184, 1982.

Berto L, Saetta A, Scotta R, Vitaliani R, Orthotropic damage model for masonry structures. International Journal for Numerical Methods in Engineering 55(2), pp. 127-157, 2002.

Cervera M, Visco-elasticity and rate-dependent continuum damage models. Centre for Numerical Methods in Engineering - CIMNE, Monograph M79, Barcelona, 2003.

Cervera M, Pelà L, Clemente R, A crack-tracking technique for localized damage in quasi-brittle materials. Engineering Fracture Mechanics, 77, pp. 2431-2450, 2010

Costa AA, Arêde A, Costa A, Guedes J, Silva B, Experimental testing, numerical modelling and seismic strengthening of traditional stone masonry: comprehensive study of a real Azorian pier. Bulletin of Earthquake Engineering, 1-25, 2010.

Costa C, Pegon P, Arêde A, Castro J, Implementation of the Damage model in Tension and Compression with Plasticity in Cast3m. Report EUR, ISPC, CEC, JRC, Ispra (VA), Itália, 2005.

De Bellis ML, Addessi D, A cosserat based multi-scale model for masonry structures. International Journal for Multiscale Computational Engineering, 9(5), 2011.

da Porto F, Silva B, Costa C, Modena C, Macro-scale analysis of damage to churches after earthquake in Abruzzo (Italy) on April 6, 2009. Journal of Earthquake Engineering, 16(6), pp. 739-758, 2012.

Endo Y, Pelà L, Roca P, da Porto F, Modena C, Comparison of seismic analysis methods applied to a historical church struck by 2009 L'Aquila earthquake. Bulletin of Earthquake Engineering, DOI 10.1007/s10518015-9796-0, 2015.

Faria R, Avaliação do comportamento sísmico de barragens de betão através de um modelo de dano contínuo. PhD Thesis, Faculdade de Engenharia da Universidade do Porto, Porto, Portugal, 1994. (in Portuguese)

Faria R, Oliver J, A rate dependent plastic-damage constitutive model for large scale computations in concrete structures. CIMNE Monograph 17, Barcelona, 1993. 
Faria R, Oliver J, Cervera M, A strain-based viscous-plastic-damage model for massive concrete structures. International journal of solids and structures, 35(14), 1533-1558, 1998.

Faria R, Pouca NV, Delgado R, Simulation of the cyclic behaviour of R/C rectangular hollow section bridge piers via a detailed numerical model. Journal of Earthquake Engineering, 8(5), 725-748, 2004.

Lagomarsino S, Gambarotta L, Damage models for the seismic response of brick masonry shear walls. Part I: The mortar joint model and its applications. Earthquake Engineering and Structural Dynamics, 26, 423439, 1997.

Lourenço PB, Computational strategies for masonry structures. Delft University of Technology, 1996.

Lourenço PB, Rots JG, A multi-surface interface model for the analysis of masonry structures. Journal of Engineering Mechanics, ASCE, 123(7), pp. 660-668, 1997.

Massart TJ, Peerlings RHJ, Geers M.G.D., Structural Damage Analysis of Masonry Walls using Computational Homogenization. International Journal of Damage Mechanics, SAGE Publications, 16 (2), pp.199-226, 2007.

Nguyen VP, Stroeven M, Sluys LJ, Multiscale continuous and discontinuous modeling of heterogeneous materials: A review on recent developments. Journal of Multiscale Modelling, 3(04), pp. 229-270, 2011.

NTC, Norme Tecniche per le costruzioni. D.M. 14/01/2008 by the Ministry of Public Works of Italy. G.U. 04/02/2008, 2008. (in Italian)

Pasquet P, Manuel d'utilisation de Cast3m. Commissariat à l'Énergie Atomique, www.cast3m.cea.fr, 2003.

Pelà L, Aprile A, Benedetti A, Seismic assessment of masonry arch bridges. Engineering Structures, 31(8), 1777-1788, 2009.

Pelà L, Cervera M, Roca P, Benedetti A, An orthotropic damage model for the analysis of masonry structures. Construction and Building Materials, 41, pp. 957-967, 2013.

Petracca M, Pelà L, Rossi R, Oller S, Camata G, Spacone E, Regularization of first order computational homogenization for multiscale analysis of masonry structures. Computational Mechanics, 57 (2), pp. 257-276, 2015.

Roca P, Massanas M, Cervera M, Arun G., Structural analysis of Küçük Ayasofya Mosque in Istanbul. Proc. IV International Seminar on Structural Analysis of Historical Constructions - SAHC04, Padova, Italy, 679686, 2004.

Roca P, Cervera M, Gariup G. Pelà L, Structural Analysis of Masonry Historical Constructions. Classical and Advanced Approaches. Arch Comput Methods Eng, 17, pp. 299-325, 2010.

Silva B, Guedes JM, Arêde A, Costa A, Calibration and application of a continuum damage model on the simulation of stone masonry structures: Gondar church as a case study. Bulletin of Earthquake Engineering, 2010.

Silva B, Diagnosis and strengthening of historical masonry structures: numerical and experimental analyses. PhD Thesis, University of Padova, Italy, 2012.

Silva B, Dalla Benetta M, da Porto F, Valluzzi MR, Compression and sonic tests to assess effectiveness of grout injection on three-leaf stone masonry walls. International Journal of Architectural Heritage, 8(3), 408435, 2014a.

Silva B, Dalla Benetta M, da Porto F, Modena C, Experimental assessment of in-plane behaviour of three-leaf stone masonry walls. Construction and Building Materials, 53, 149-161, 2014b.

Silva B, Pigouni AE, Valluzzi MR, Modena C, Calibration of analytical formulations predicting compressive strength in consolidated three-leaf masonry walls. Construction and Building Materials, 64, 28-38, 2014c.

Turnšek V, Cacovic F, Some experimental results on the strength of brick masonry walls. Proc. $2^{\text {nd }}$ International Brick Masonry Conference, 149-156. Stoke-on-Trent, Great Britain, 1971.

Turnšek V, Sheppard P, The shear and flexural resistance of masonry walls. Proc. Research Conference on Earthquake Engineering, Skopje, Republic of Macedonia, 517-573, 1980. 


\section{List of Tables}

Table 1 Compression tests results.

Table 2 Strength and ductility indicators.

Table 3 Continuum damage model parameters for cyclic compression.

Table 4 Continuum damage model parameters - tensile branch.

Table 5 Parameters for shear-compression tests.

Table 6 Variation of the parameter values.

Table 7 Numerical and experimental maximum horizontal load $\left(\mathrm{H}_{\max }\right)$, displacement at maximum load $\left(\delta_{\mathrm{H} \max }\right)$ and ultimate displacement $\left(\delta_{\mathrm{u}}\right)$. 


\section{List of Figures}

Fig. 1 Setup for compression tests, (Silva et al. 2014a).

Fig. 2 Setup for shear-compression tests, (Silva et al. 2014b).

Fig. 3 Schematization of the four Limit States.

Fig. 4 Hysteretic curves, (Silva et al. 2014b): (a) $\mathrm{SCF}_{1.0 \mathrm{NI}}$ (b) $\mathrm{SCF}_{1.0 \mathrm{I}}$.

Fig. 5 Limit state envelope curves, (Silva et al. 2014b), for (a) 1:1 scale specimens and (b) 2:3 scale specimens.

Fig. 6 Cyclic behaviour obtained with this model, (Faria, 1994): (a) Uniaxial tensile and (b) Uniaxial compression.

Fig. 7 Experimental and numerical curves of uniaxial compression tests. (a) Monotonic test of original panels in scale 1:1. (b) Cyclic test of original panels in scale $1: 1$.

Fig. 8 Finite element model: mesh, boundary conditions and loads (a); experimental test (b).

Fig. 9 Material behaviour laws: (a) compression; (b) tension.

Fig. 10 Experimental and numerical load-displacement envelope curves: (a) SC3LF I.ONI $_{\text {. (b) SC3LF }}$.0I. (c) $\mathrm{SC} \mathrm{LS}_{0.75 \mathrm{NI}}$. (d) SC3LS $1.5 \mathrm{I}$.

Fig. 11 Tensile damage $\left(\mathrm{d}^{+}\right)$propagation in panel $\mathrm{SC} 3 \mathrm{LF}_{1.25 \mathrm{NI}}$.

Fig. 12 Crack pattern at $\delta_{\mathrm{u}}$, panel SC3LF $\mathrm{LF}_{1.25 \mathrm{NI}}$ : (a) in-plane; (b) out-of-plane.

Fig. 13 Results of parametric shear-compression analyses.

Fig. 14 Comparison between analytical formulations, numerical analysis and experimental results.

Fig. 15 Results of parametric shear-compression analyses: $\psi_{\delta u}$ and $\psi_{\mathrm{H} \max }$ for scale 1:1 panels (F) injected and original.

Fig. 16 Parametric shear-compression analysis - Panels $H_{\max }$ vs. $\psi_{\delta u}$ curves.

Fig. 17 Parametric shear-compression analysis - $\mathrm{H}_{\max }$ vs. $\psi_{\mathrm{Hmax}}$.

Fig. 18 Damage pattern for 2:3 injected panels with slenderness of 1.0. (a) $40 \%$ of $\sigma_{\max }$. (b) $70 \%$ of $\sigma_{\max }$. 


\section{List of Figures}
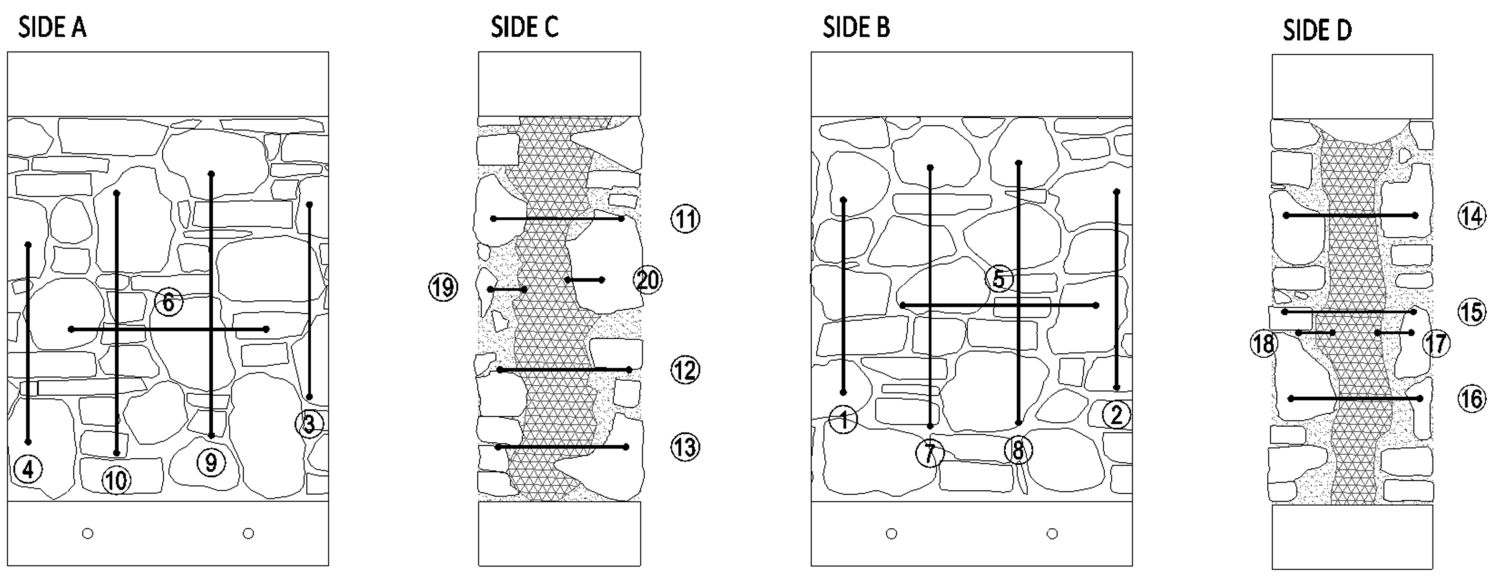

Fig. 1 Setup for compression tests, (Silva et al. 2014a).

Full scale $1: 1$ panels $-100 \mathrm{~mm}$ of width $\mathrm{x} 120 \mathrm{~mm}$ of height $\mathrm{x} 50 \mathrm{~mm}$ thick Reduced scale 2:3 panels - $80 \mathrm{~mm}$ of width $\times 100 \mathrm{~mm}$ of height $\mathrm{x} 33 \mathrm{~mm}$ thick
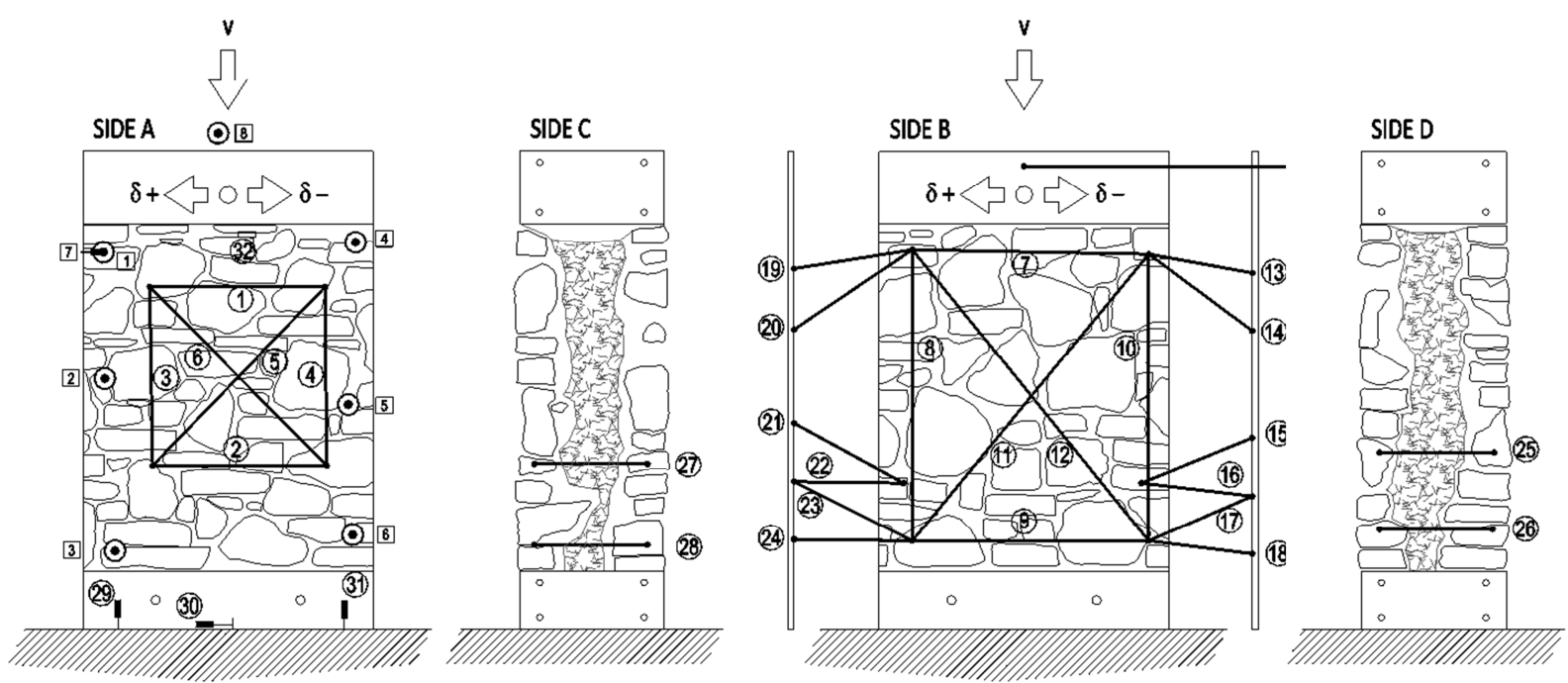

Fig. 2 Setup for shear-compression tests, (Silva et al. 2014b). 


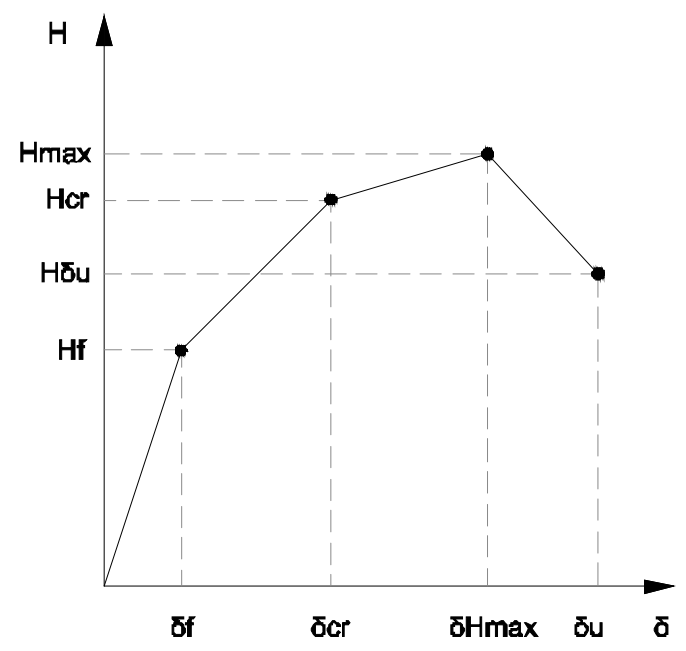

Fig. 3 Schematization of the four Limit States.

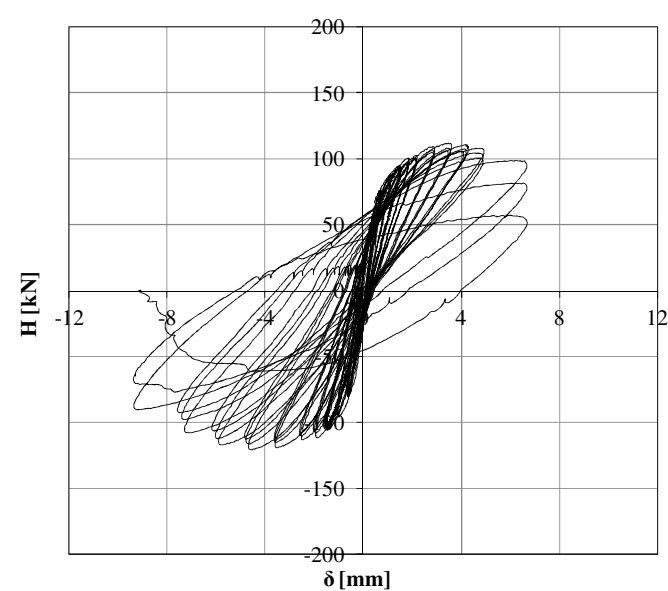

(a)

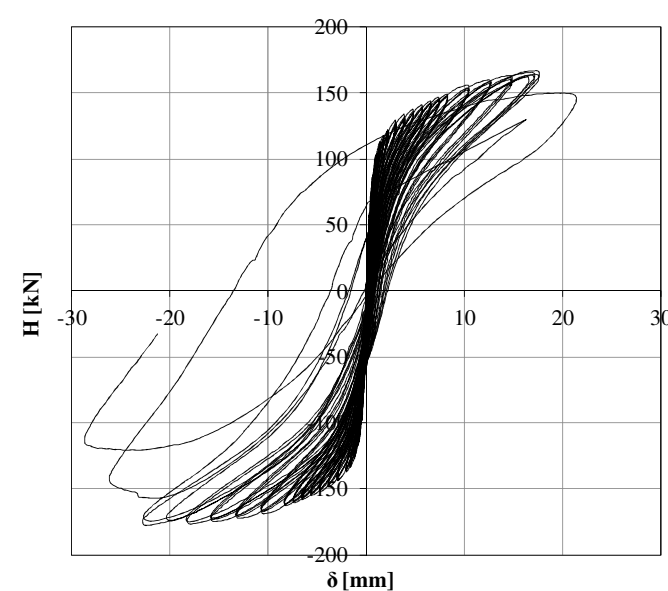

(b)

Fig. 4 Hysteretic curves, (Silva et al. 2014b): (a) $\mathrm{SCF}_{1.0 \mathrm{NI}}$ (b) $\mathrm{SCF}_{1.0 \mathrm{I}}$.

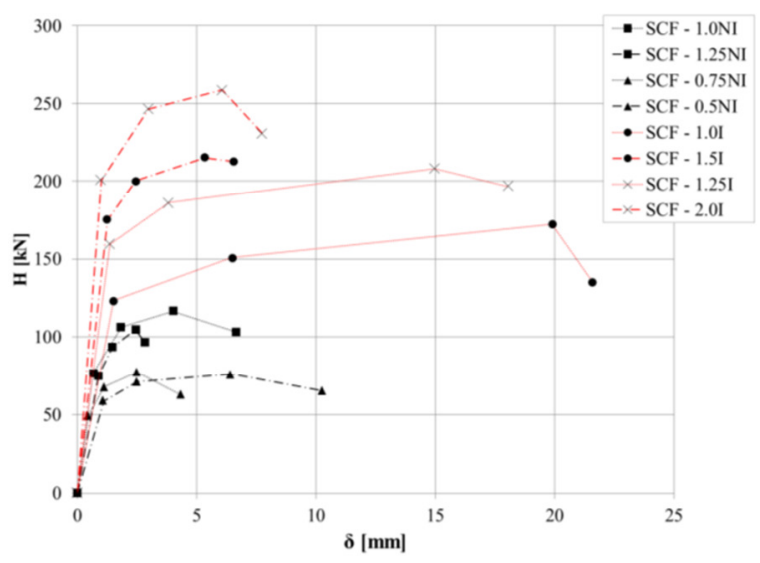

(a)

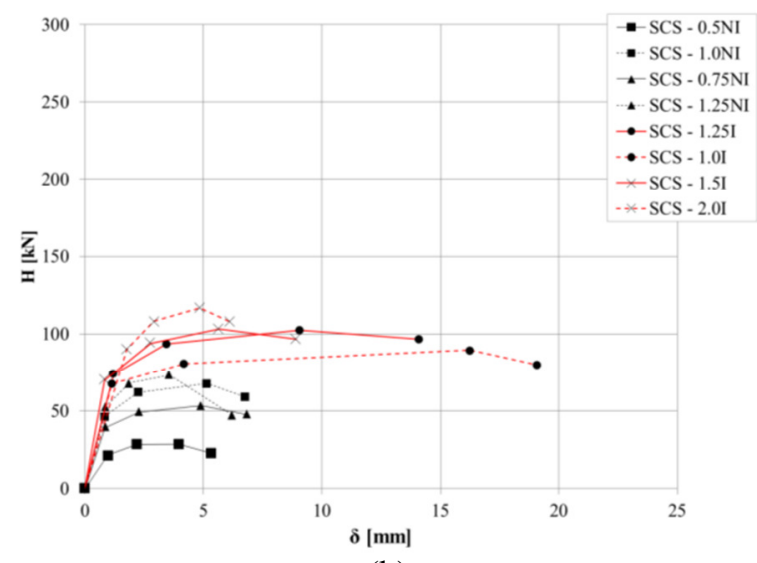

(b)

Fig. 5 Limit state envelope curves, (Silva et al. 2014b), for (a) 1:1 scale specimens and (b) 2:3 scale specimens. 


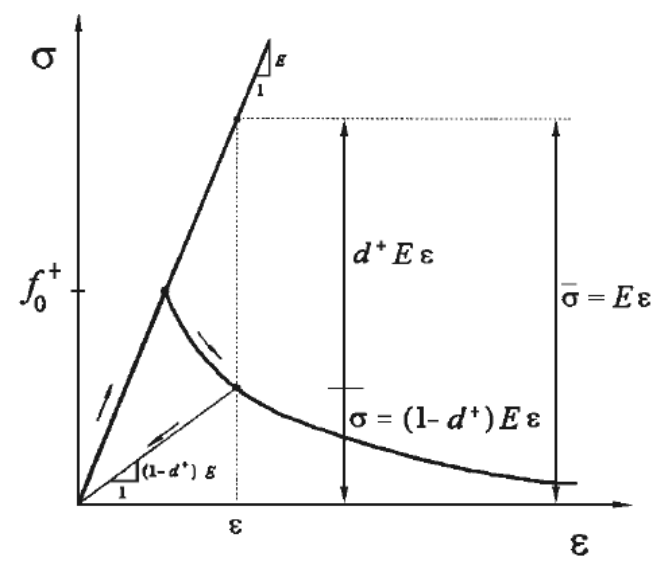

(a)

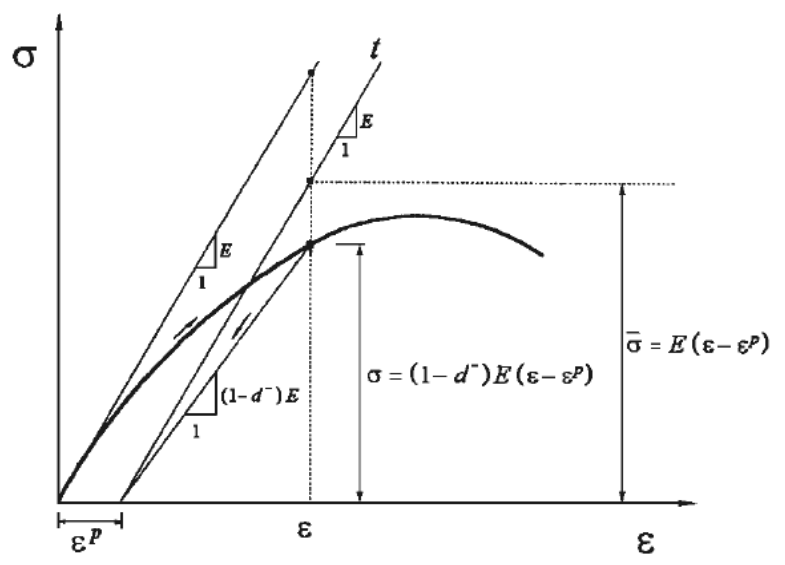

(b)

Fig. 6 Cyclic behaviour obtained with this model, (Faria, 1994): (a) Uniaxial tensile and (b) Uniaxial compression.

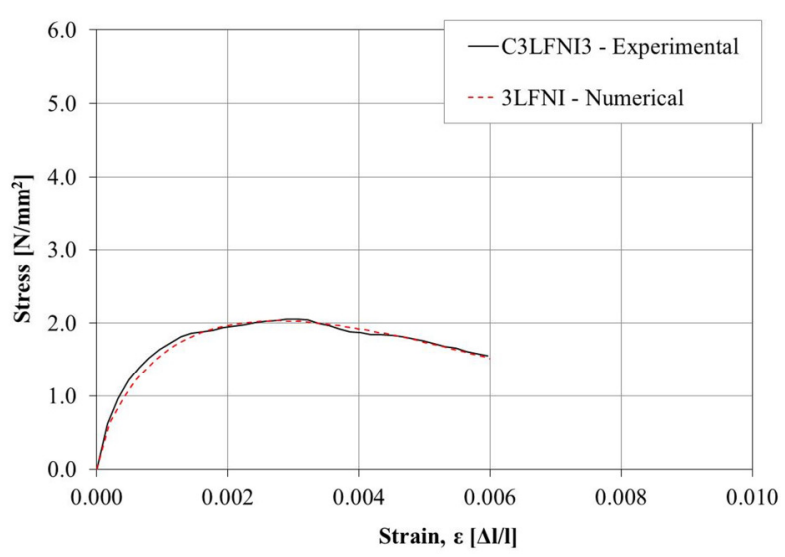

(a)

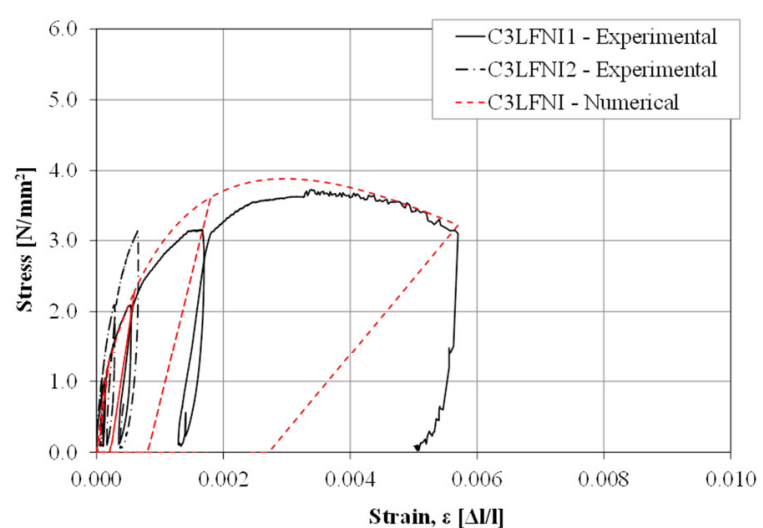

(b)

Fig. 7 Experimental and numerical curves of uniaxial compression tests. (a) Monotonic test of original panels in scale 1:1. (b) Cyclic test of original panels in scale 1:1. 

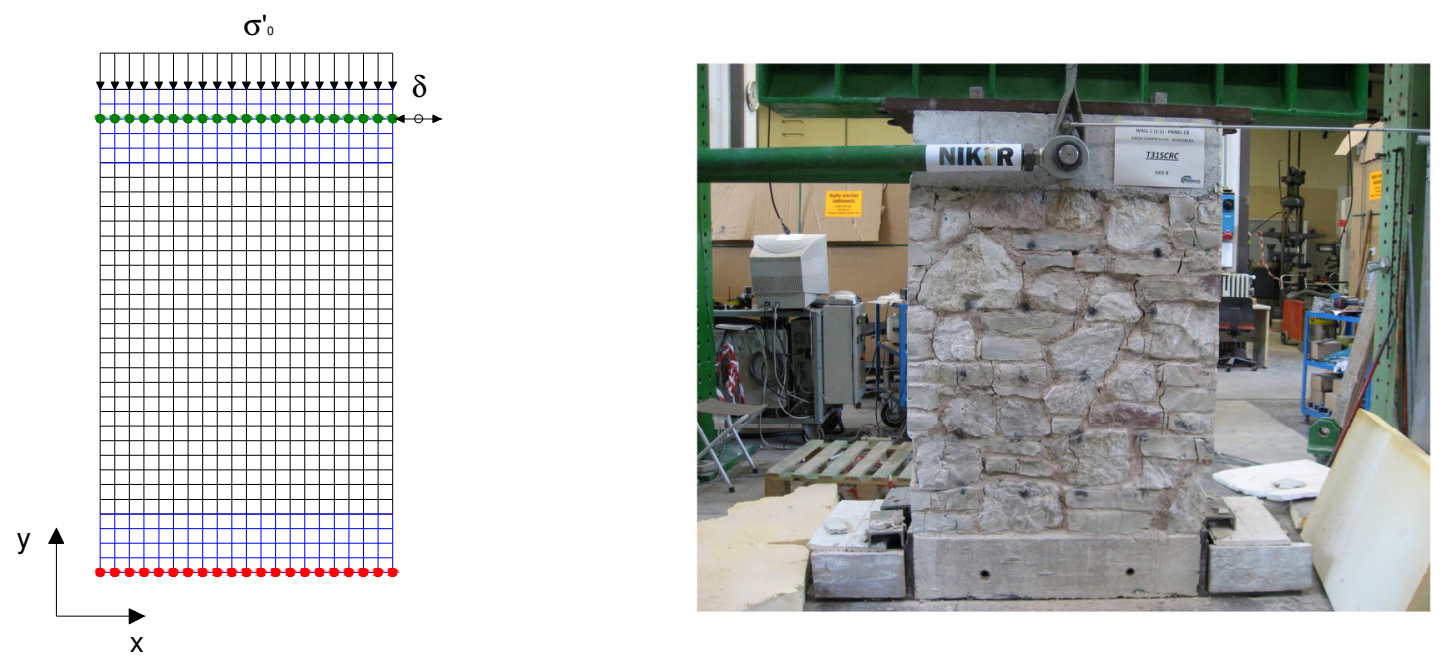

$\square$ Masonry (8 node elements - QUA8)

$\square \quad$ RC Beam (8 node elements - QUA8)

- Application of the horizontal displacement law

- Base boundary conditions (Ux and Uy blocked)

(a)

(b)

Fig. 8 Finite element model: mesh, boundary conditions and loads (a); experimental test (b).

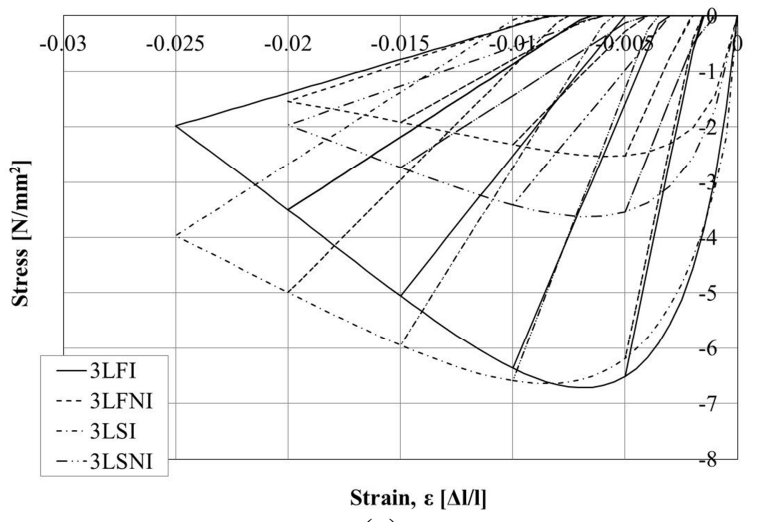

(a)

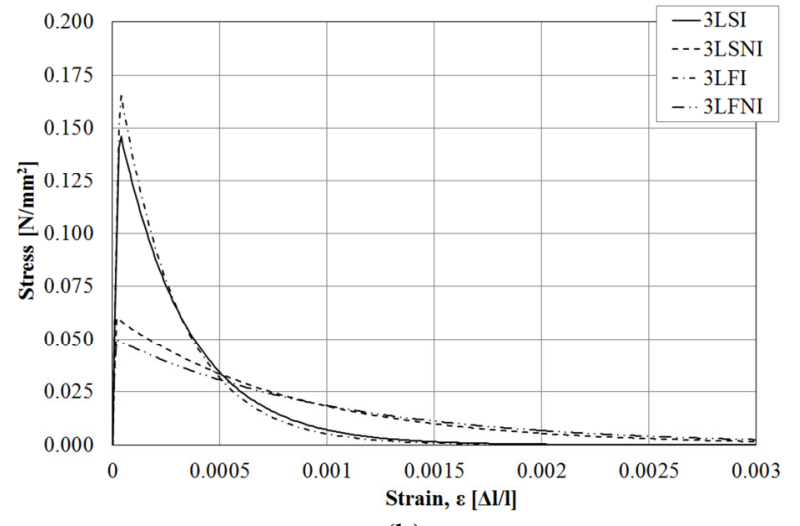

(b)

Fig. 9 Material behaviour laws: (a) compression; (b) tension. 


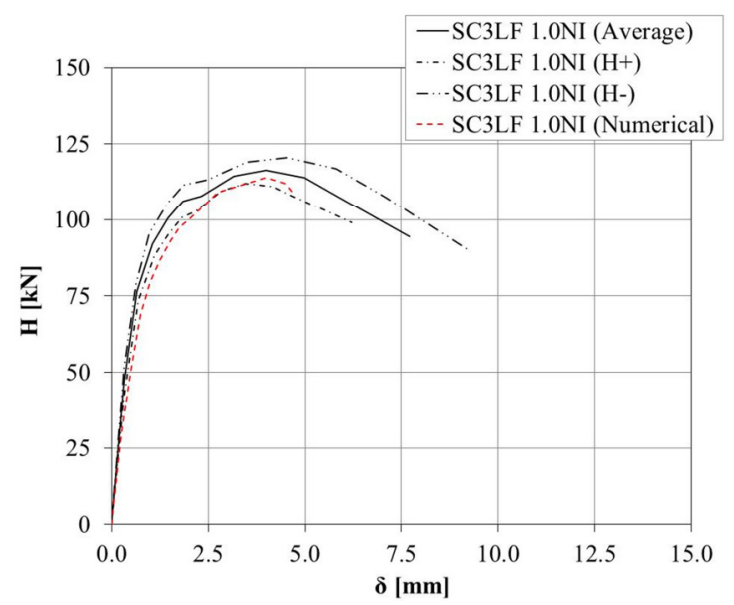

(a)

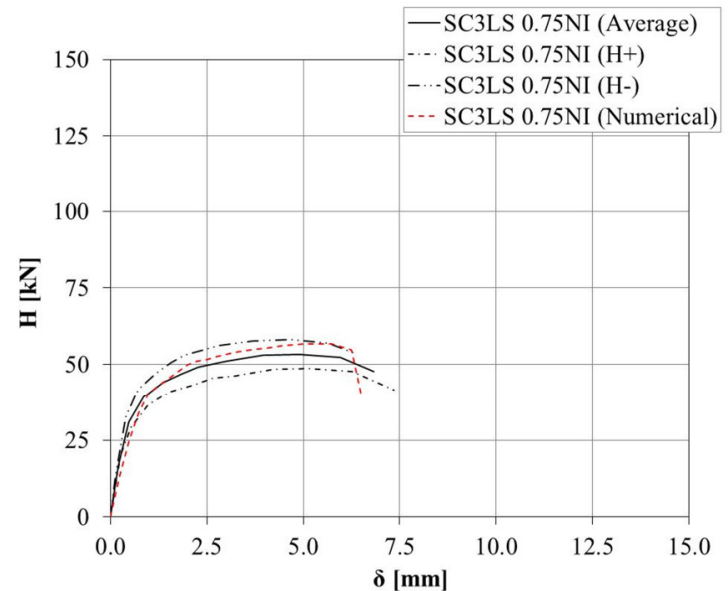

(c)

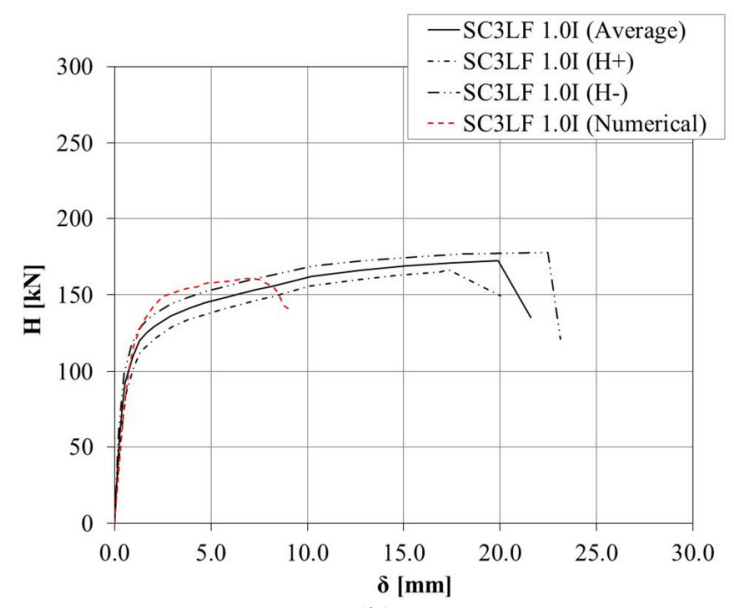

(b)

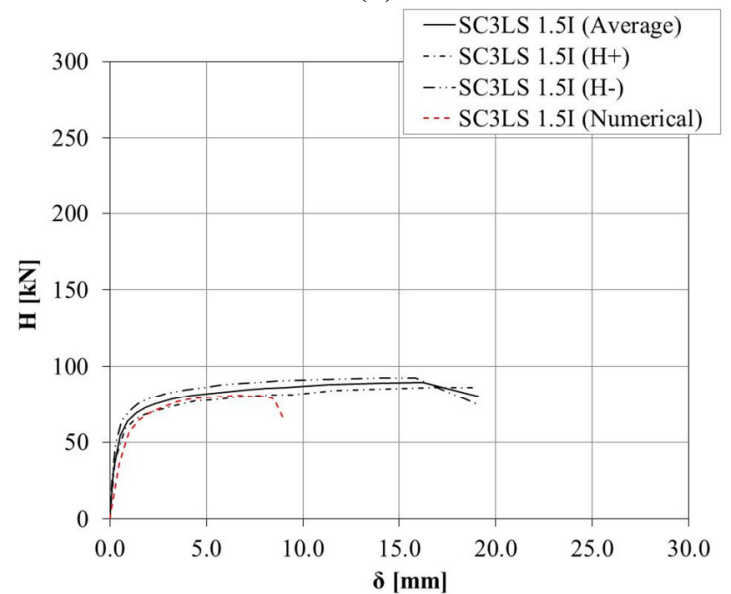

(d)

Fig. 10 Experimental and numerical load-displacement envelope curves: (a) SC3LF $1.0 \mathrm{NI}$. (b) SC3LF $\mathrm{L}_{1.0 \mathrm{I}}$. (c) $\mathrm{SC} \mathrm{LS}_{0.75 \mathrm{NI} \cdot}$ (d) SC3LS $1.5 \mathrm{I}$.

$\sigma^{\prime}$

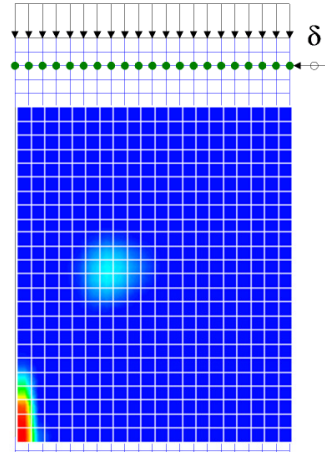

$-1 \mathrm{~mm}$ $\sigma_{0}^{\prime}$

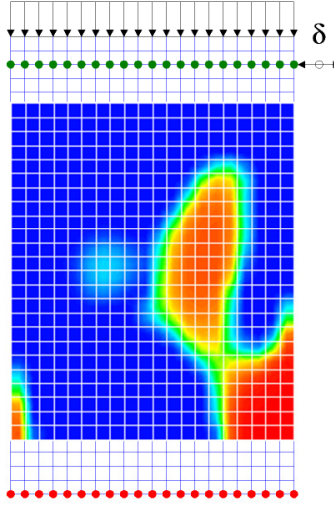

$2 \mathrm{~mm}$ $\sigma^{\prime}$

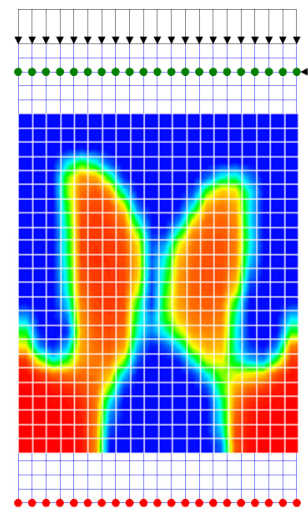

$-2 \mathrm{~mm}$ $\sigma_{0}^{\prime}$

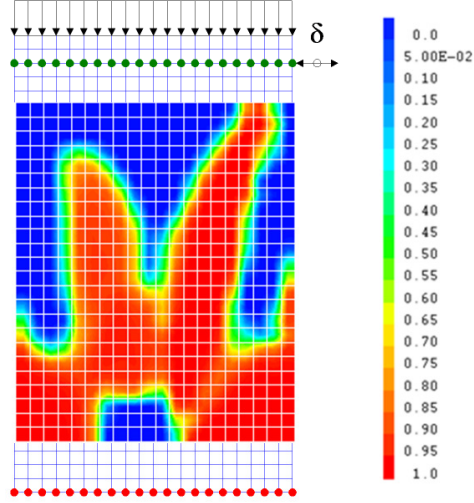

$3.2 \mathrm{~mm}\left(\delta_{\mathrm{u}}\right)$

Fig. 11 Tensile damage $\left(\mathrm{d}^{+}\right)$propagation in panel $\mathrm{SC}_{2} \mathrm{LF}_{1.25 \mathrm{NI}}$. 


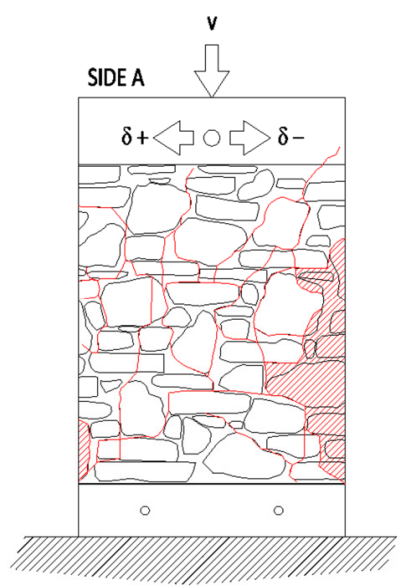

(a)

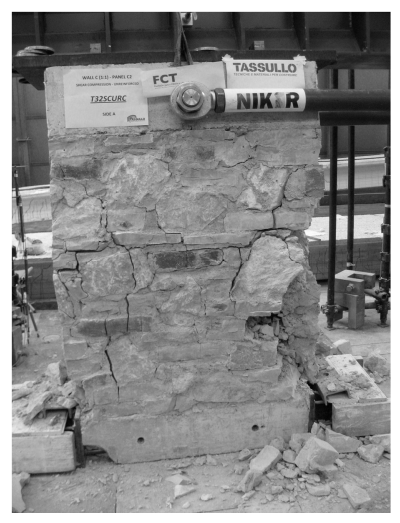

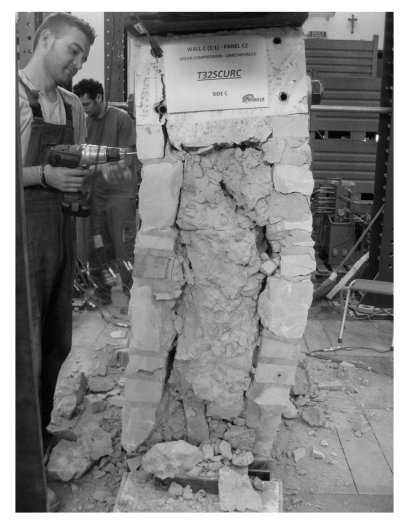

(b)

Fig. 12 Crack pattern at $\delta_{u}$, panel SC3LF ${ }_{1.25 N I}$ : (a) in-plane; (b) out-of-plane.
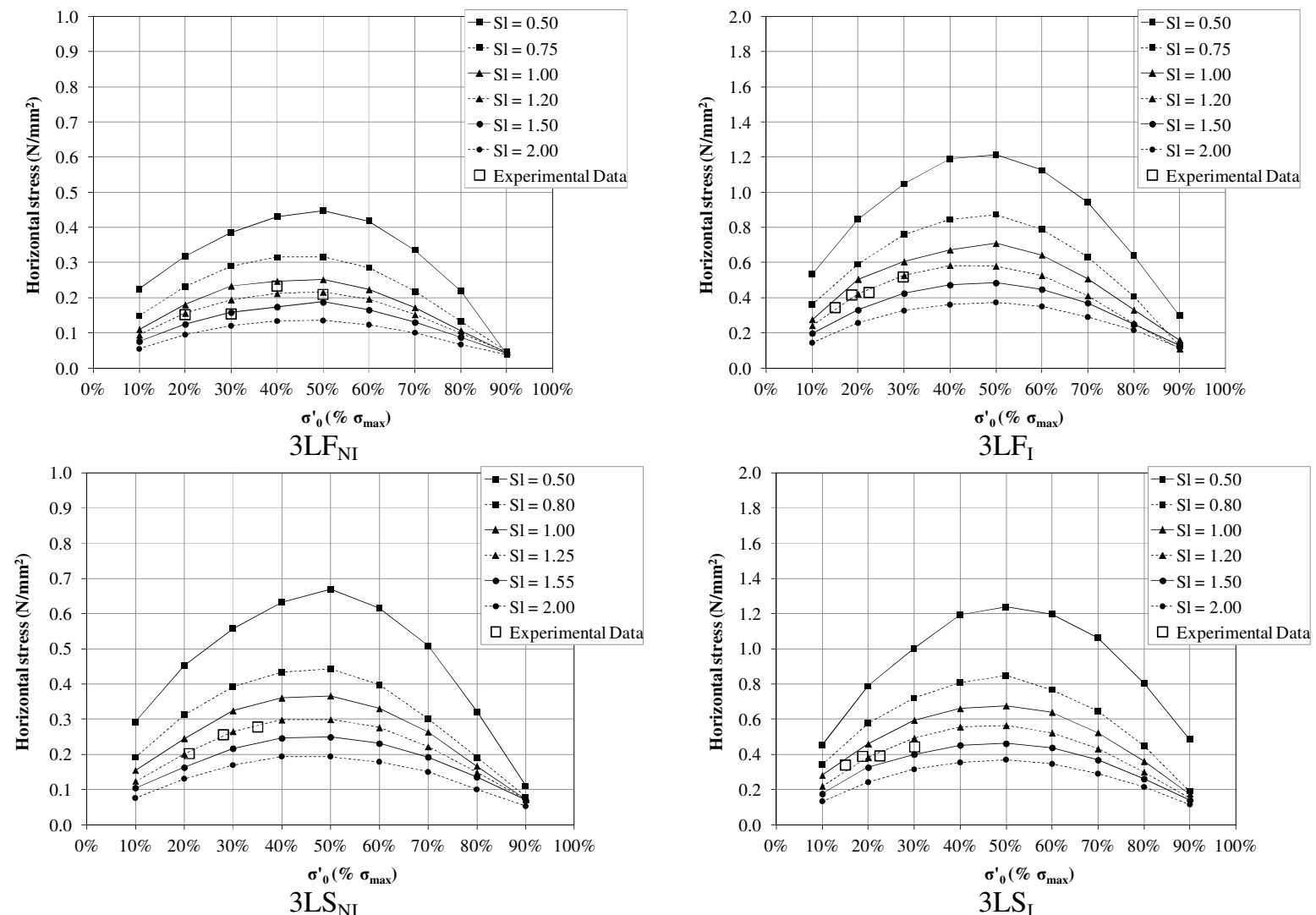

Fig. 13 Results of parametric shear-compression analyses 


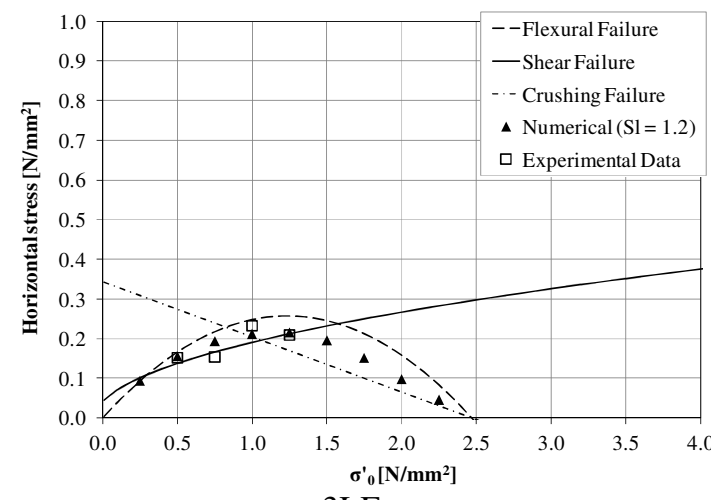

$3 \mathrm{LF}_{\mathrm{NI}}$

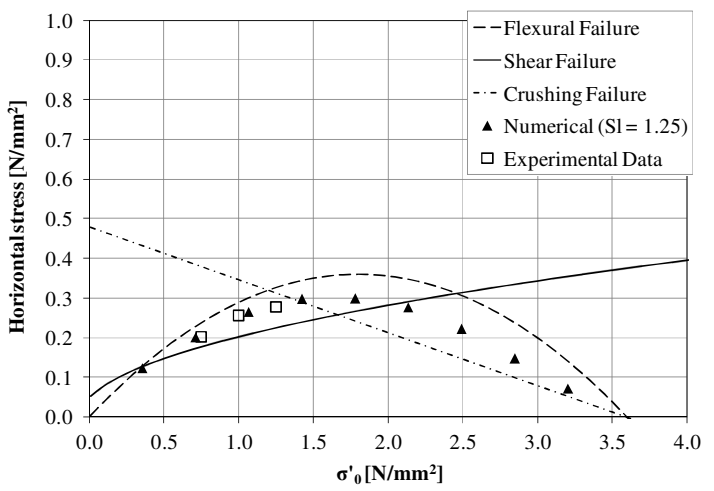

$3 \mathrm{LS}_{\mathrm{NI}}$

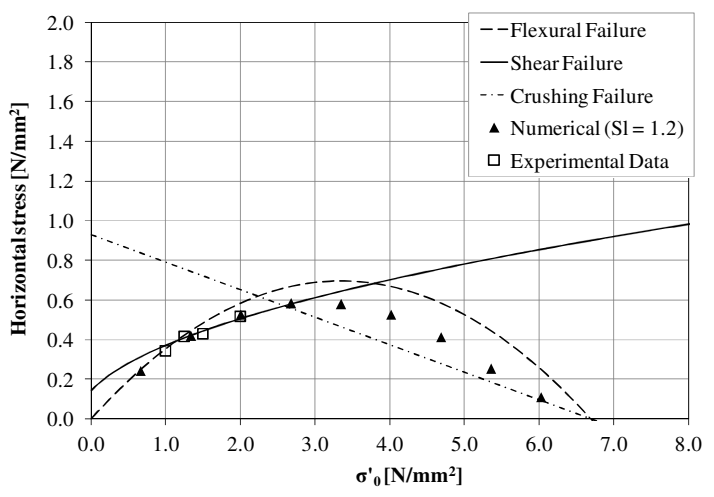

$3 \mathrm{LF}_{\mathrm{I}}$

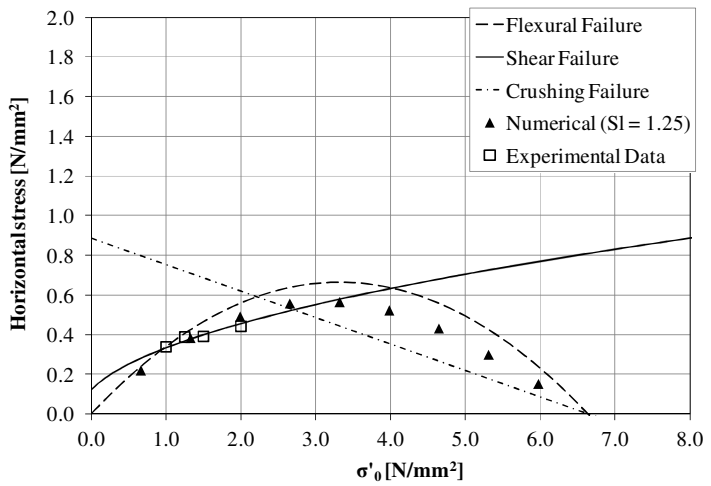

$3 \mathrm{LS}_{\mathrm{I}}$

Fig. 14 Comparison between analytical formulations, numerical analysis and experimental results. 

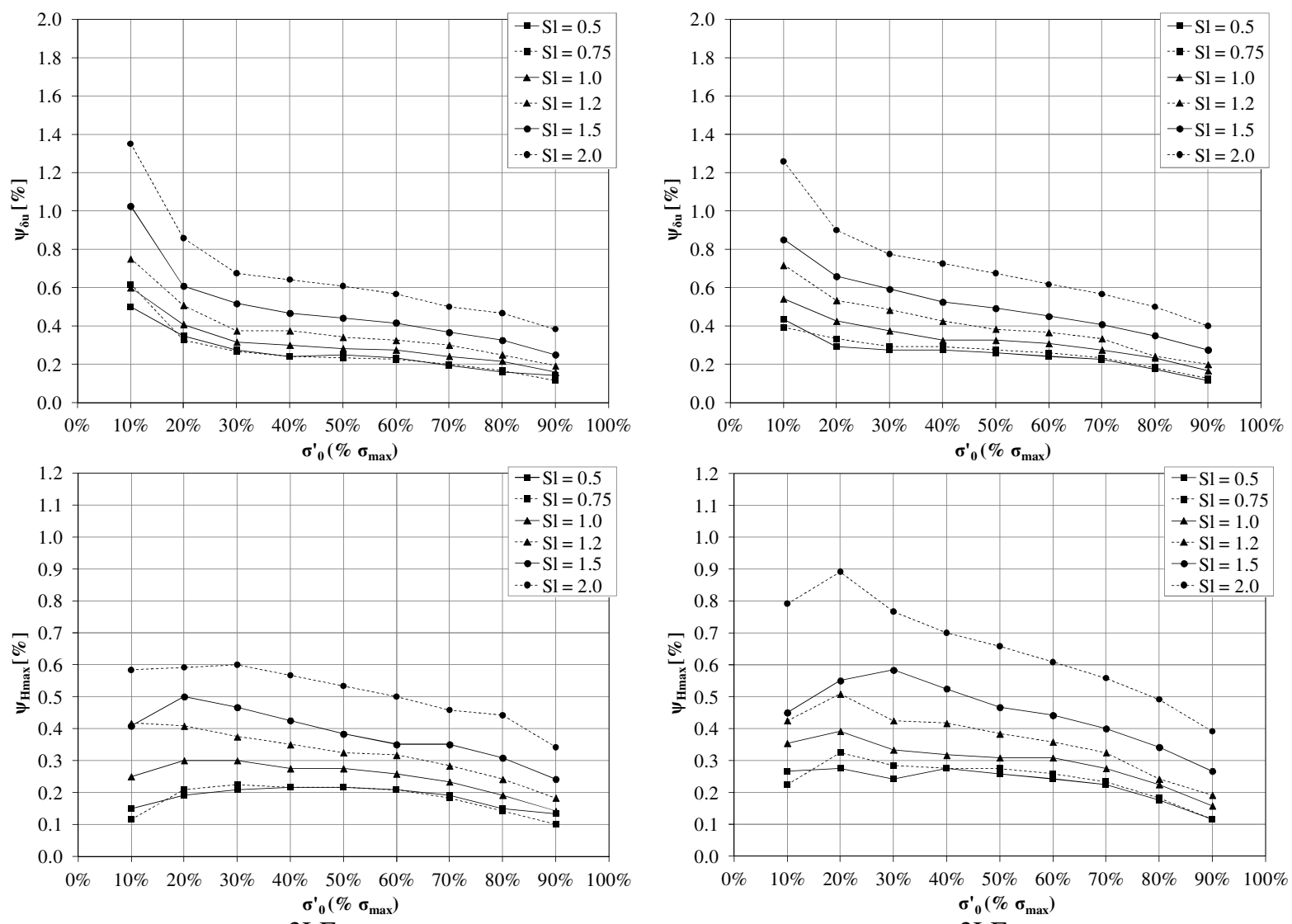

$3 \mathrm{LF}_{\mathrm{NI}}$

$3 \mathrm{LF}_{\mathrm{I}}$

Fig. 15 Results of parametric shear-compression analyses: $\psi_{\delta u}$ and $\psi_{\mathrm{H} \max }$ for scale 1:1 panels (F) injected and original. 

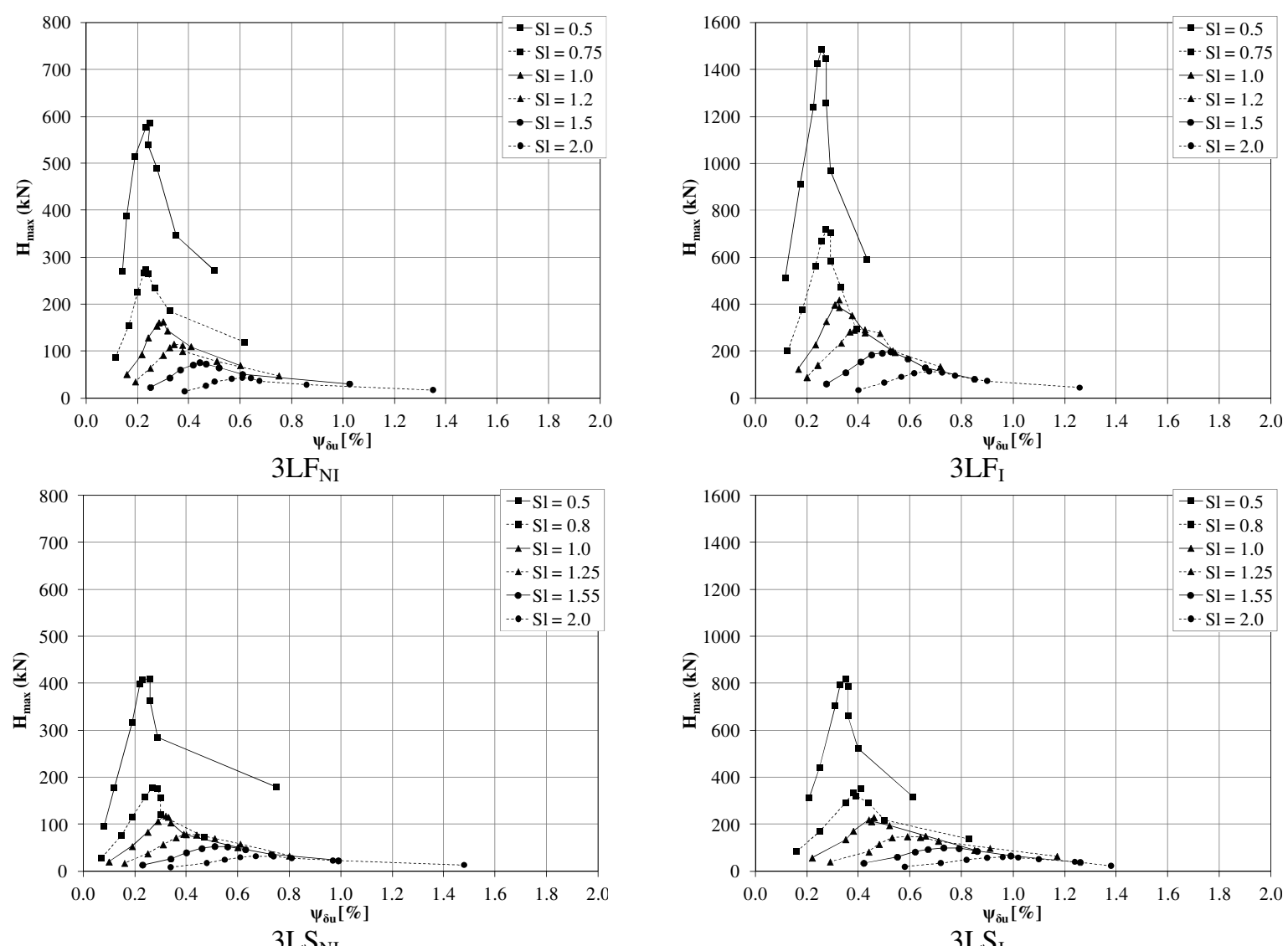

Fig. 16 Parametric shear-compression analysis - Panels $H_{\max }$ vs. $\psi_{\delta u}$ curves. 

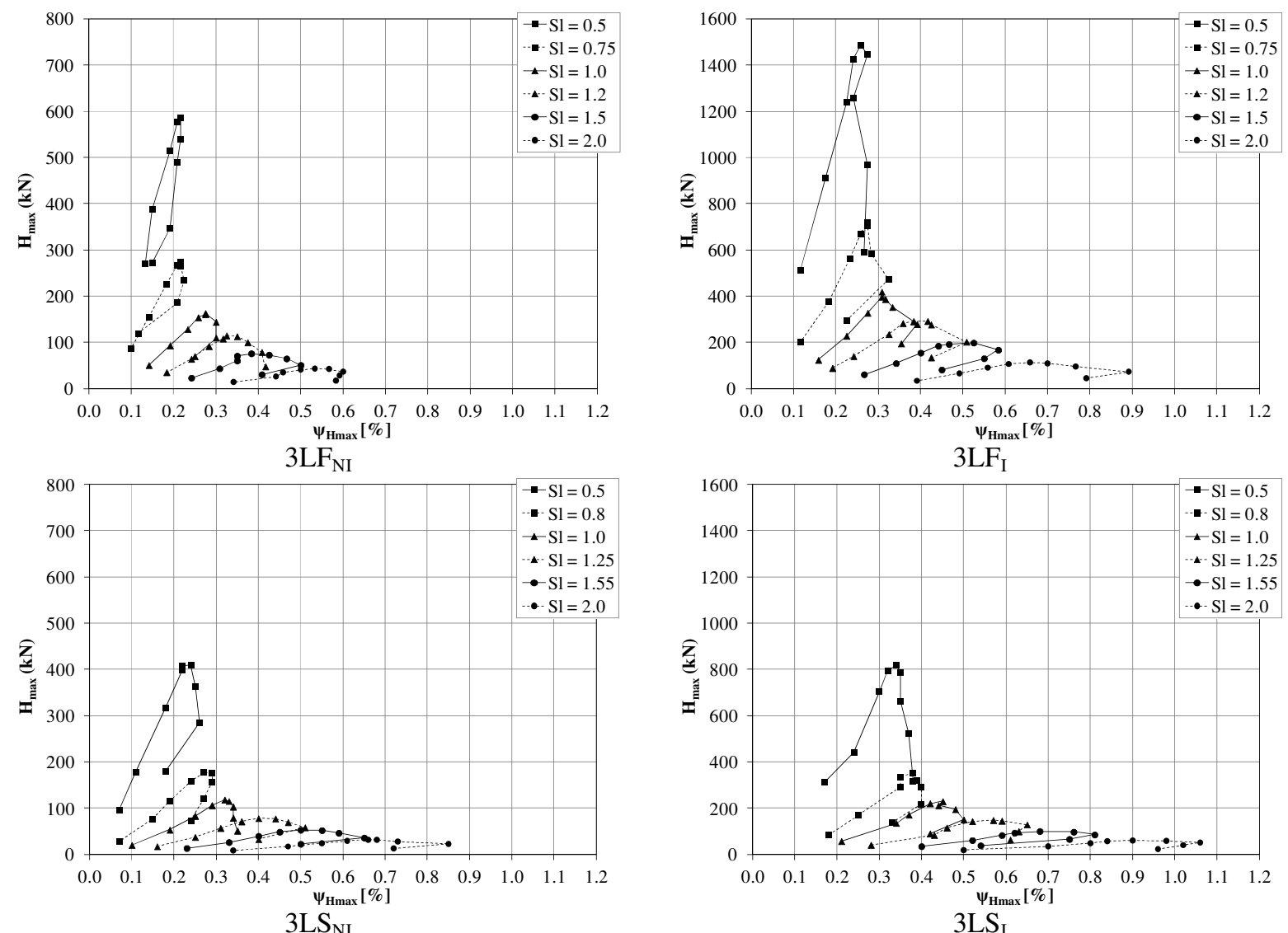

Fig. 17 Parametric shear-compression analysis $-\mathrm{H}_{\max }$ vs. $\psi_{\mathrm{H} \max }$.

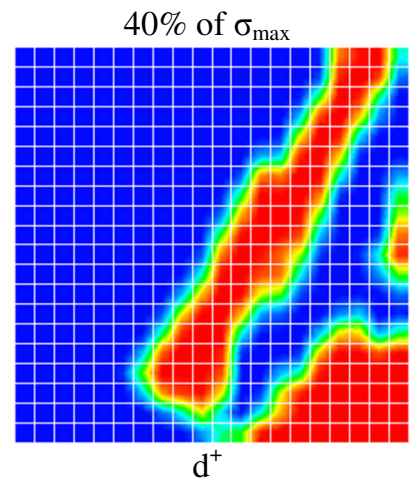

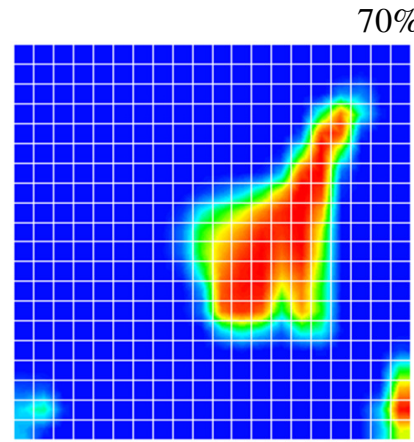

$\mathrm{d}^{+}$

$70 \%$ of $\sigma_{\max }$

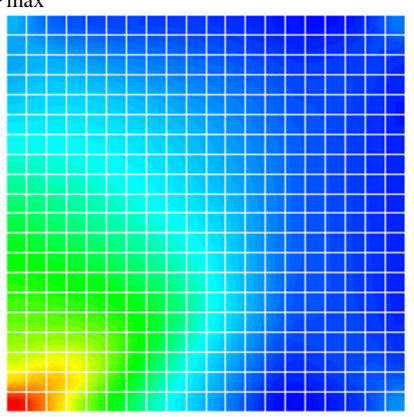

$\mathrm{d}^{-}$ (a)

(b)

Fig. 18 Damage pattern for 2:3 injected panels with slenderness of 1.0. (a) $40 \%$ of $\sigma_{\max }$. (b) $70 \%$ of $\sigma_{\max }$. 


\section{List of Tables}

Table 1 Compression tests results.

\begin{tabular}{|c|c|c|c|c|c|c|c|c|}
\hline Panels & Type & $\begin{array}{c}\text { Dimension } \\
\left(\begin{array}{c}\boldsymbol{x} \\
\boldsymbol{t}\end{array} \boldsymbol{x} \boldsymbol{h}\right) \\
{[\mathrm{mm}]}\end{array}$ & Scale & Condition & $\begin{array}{c}\sigma_{\max } \\
{\left[\mathrm{N} / \mathbf{m m}^{2}\right]}\end{array}$ & $\begin{array}{c}f_{1, c r} \\
{\left[N / \mathrm{mm}^{2}\right]}\end{array}$ & $\begin{array}{c}f_{1, c r} / \sigma_{\max } \\
{[\%]}\end{array}$ & $\begin{array}{c}E_{10 \%-40 \%} \\
{\left[N / m^{2}\right]}\end{array}$ \\
\hline 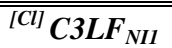 & \multirow{12}{*}{$3 L$} & \multirow{6}{*}{$100 \times 50 \times 120$} & \multirow{6}{*}{$1: 1(F)$} & \multirow{3}{*}{$N I$} & 2.9 & 0.7 & 24 & 2415 \\
\hline${ }^{[C l]} \mathrm{C} \mathrm{LF}_{N I 2}$ & & & & & 2.5 & 1.1 & 46 & 2294 \\
\hline${ }^{[M]} C 3 L F_{N I 3}$ & & & & & 2.1 & 0.4 & 21 & 2885 \\
\hline${ }^{[C l]} \mathrm{C}^{2} \mathrm{LF}_{I I}$ & & & & \multirow{3}{*}{$I$} & 3.7 & 2.0 & 54 & 4725 \\
\hline${ }^{[C l]} \mathrm{C} \mathrm{LF}_{I 2}$ & & & & & 4.9 & 2.1 & 43 & 6781 \\
\hline${ }^{[M]} C_{3 L F} F_{13}$ & & & & & 4.2 & 0.7 & 16 & 4103 \\
\hline${ }^{[C l]} \mathrm{C} 3 \mathrm{LS} S_{N I I}$ & & \multirow{6}{*}{$80 \times 33 \times 100$} & \multirow{6}{*}{$2: 3(S)$} & \multirow{3}{*}{$N I$} & 2.2 & 1.4 & 64 & 1726 \\
\hline${ }^{[M]} C 3 L S_{N I 2}$ & & & & & 2.8 & 1.6 & 56 & 2813 \\
\hline${ }^{[C l]} \mathrm{C} 3 \mathrm{LS}_{\mathrm{NI3}}$ & & & & & 2.2 & 1.5 & 68 & 2636 \\
\hline${ }^{[M]} C 3 L S_{I I}$ & & & & \multirow{3}{*}{$I$} & 5.4 & 4.4 & 81.0 & 5030 \\
\hline${ }^{[C l]} C 3 L S_{I 2}$ & & & & & 4.0 & 2.7 & 66 & 5708 \\
\hline${ }^{[C l]} \mathrm{C} 3 \mathrm{LS}_{\mathrm{I3}}$ & & & & & 5.3 & 1.6 & 30 & 4637 \\
\hline \multicolumn{5}{|c|}{${ }^{[M]}$ Monotonic load } & \multicolumn{4}{|c|}{$3 L-$ three-leaf stone masonry panels } \\
\hline \multicolumn{4}{|c|}{${ }^{[C l]}$ Cyclic load } & \multicolumn{5}{|c|}{$F$ - full scale panels (1:1) } \\
\hline \multicolumn{4}{|l|}{$t$ - thickness } & \multicolumn{5}{|c|}{$S$ - reduced scale panels (2:3) } \\
\hline \multicolumn{4}{|l|}{ I- width } & \multicolumn{5}{|c|}{$\mathrm{NI}$ - original conditions } \\
\hline \multicolumn{4}{|l|}{$h$ - height } & \multicolumn{5}{|c|}{ I - consolidated with grout injection } \\
\hline
\end{tabular}


Table 2 Strength and ductility indicators.

\begin{tabular}{|c|c|c|c|c|c|c|c|}
\hline Panels & $\begin{array}{c}\sigma_{0}^{\prime} \\
{\left[N / \mathbf{m m}^{2}\right]}\end{array}$ & $\boldsymbol{H}_{c r} / \boldsymbol{H}_{\max }$ & $H_{\delta u} / H_{\max }$ & $\boldsymbol{H}_{\delta u} / \boldsymbol{H}_{c r}$ & $\delta_{c r} / \delta_{H \max }$ & $\delta_{u} / \delta_{\text {Hmax }}$ & $\delta_{u} / \delta_{c r}$ \\
\hline 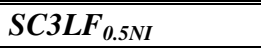 & 0.5 & 0.93 & 0.86 & 0.92 & 0.39 & 1.60 & 4.10 \\
\hline$S C 3 L F_{0.75 N I}$ & 0.75 & 0.88 & 0.81 & 0.92 & 0.46 & 1.74 & 3.83 \\
\hline$S C 3 L F_{1.0 N I}$ & 1.0 & 0.91 & 0.89 & 0.97 & 0.46 & 1.66 & 3.61 \\
\hline$S C 3 L F_{1.25 N I}$ & 1.25 & 0.89 & 0.92 & 1.04 & 0.60 & 1.16 & 1.93 \\
\hline Average & & 0.90 & 0.87 & 0.96 & 0.48 & 1.54 & 3.37 \\
\hline$S C 3 L F_{1.0 I}$ & 1.0 & 0.87 & 0.79 & 0.90 & 0.33 & 1.09 & 3.34 \\
\hline$S C 3 L F_{1.25 I}$ & 1.25 & 0.89 & 0.94 & 1.06 & 0.26 & 1.21 & 4.71 \\
\hline$S C 3 L F_{1.5 I}$ & 1.5 & 0.93 & 0.99 & 1.06 & 0.46 & 1.22 & 2.65 \\
\hline$S C 3 L F_{2.0 I}$ & 2.0 & 0.95 & 0.89 & 0.94 & 0.49 & 1.28 & 2.60 \\
\hline Average & & 0.91 & 0.90 & 0.99 & 0.38 & 1.20 & 3.32 \\
\hline$S C 3 L S_{0.5 N I}$ & 0.5 & 0.55 & 1.35 & 2.46 & 1.48 & 0.88 & 0.60 \\
\hline$S C 3 L S_{0.75 N I}$ & 0.75 & 0.92 & 0.89 & 0.97 & 0.46 & 1.39 & 3.00 \\
\hline$S C 3 L S_{1.0 N I}$ & 1.0 & 0.92 & 0.87 & 0.95 & 0.44 & 1.31 & 3.00 \\
\hline$S C 3 L S_{1.25 N I}$ & 1.25 & 0.93 & 0.64 & 0.69 & 0.53 & 1.74 & 3.32 \\
\hline Average $^{[I]}$ & & 0.92 & 0.80 & 0.87 & 0.47 & 1.48 & 3.11 \\
\hline$S C 3 L S_{1.0 I}$ & 1.0 & 0.90 & 0.89 & 0.99 & 0.26 & 1.17 & 4.56 \\
\hline$S C 3 L S_{1.25 I}$ & 1.25 & 0.91 & 0.94 & 1.03 & 0.38 & 1.56 & 4.11 \\
\hline$S C 3 L S_{1.5 I}$ & 1.5 & 0.91 & 0.94 & 1.03 & 0.49 & 1.57 & 3.20 \\
\hline$S C 3 L S_{2.0 I}$ & 2.0 & 0.93 & 0.92 & 1.00 & 0.60 & 1.26 & 2.11 \\
\hline Average & & 0.91 & 0.92 & 1.01 & 0.43 & 1.39 & 3.50 \\
\hline
\end{tabular}

${ }^{[1]}$ Average value not including the damaged panel SC $3 L S_{0.5 \mathrm{NI}}$. 
Table 3 Continuum damage model parameters for cyclic compression.

\begin{tabular}{|c|c|c|c|c|c|c|}
\hline & & Parameters & $3 \mathrm{LF}_{\mathrm{NI}}$ & $3 \mathrm{LF}_{\mathrm{I}}$ & $3 \mathrm{LS}_{\mathrm{NI}}$ & $3 \mathrm{LS}_{\mathrm{I}}$ \\
\hline 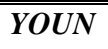 & 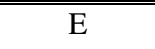 & Elastic modulus - 10 to $40 \%$ of $\sigma_{\max }\left[\mathrm{N} / \mathrm{mm}^{2}\right]$ & $3.0 \cdot 10^{3}$ & $5.8 \cdot 10^{3}$ & $2.2 \cdot 10^{3}$ & 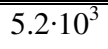 \\
\hline$N U$ & $v$ & Poisson ratio $-40 \%$ and $60 \%$ of $\sigma_{\max }[-]$ & 0.19 & 0.12 & 0.19 & 0.12 \\
\hline RHO & $\rho$ & Density $\left[\mathrm{kg} / \mathrm{m}^{3}\right]$ & 2200 & 2500 & 2200 & 2500 \\
\hline FCO1 & $\mathrm{f}_{0}^{-}$ & Elastic limit compressive stress $\left[\mathrm{N} / \mathrm{mm}^{2}\right]$ & -0.9 & -2.0 & -1.5 & -2.0 \\
\hline RT45 & $\mathrm{f}_{0,2 \mathrm{D}^{-}} / \mathrm{f}_{0,1 \mathrm{D}}^{-}$ & Equi-biaxial compressive Ratio [-] & 1 & 1 & 1 & 1 \\
\hline FCU1 & $\mathrm{f}_{\mathrm{u}}^{-}$ & Compressive peak stress $\left[\mathrm{N} / \mathrm{mm}^{2}\right]$ & -2.60 & -4.30 & -2.20 & -4.60 \\
\hline$E X T U$ & $\varepsilon_{\mathrm{u}}^{-}$ & Ultimate limit strain [-] & -0.005 & -0.0057 & -0.0043 & -0.005 \\
\hline EXTP & $\varepsilon^{\mathrm{p}-}$ & Reference strain for plastic parameter [-] & -0.0009 & -0.0020 & -0.0012 & -0.0012 \\
\hline STRP & $\sigma^{\mathrm{p}-}$ & Reference stress for plastic parameter $\left[\mathrm{N} / \mathrm{mm}^{2}\right]$ & -1.80 & -3.70 & -1.90 & -3.60 \\
\hline EXT1 & $\varepsilon_{1}^{-}$ & Fitting point 1 - Strain $[-]$ & -0.0009 & -0.0020 & -0.0012 & -0.0012 \\
\hline STR1 & $\sigma_{1}^{-}$ & Fitting point 1 - Stress $\left[\mathrm{N} / \mathrm{mm}^{2}\right]$ & -1.80 & -3.70 & -1.90 & -3.60 \\
\hline EXT2 & $\varepsilon_{2}^{-}$ & Fitting point 2 - Strain $[-]$ & -0.005 & -0.0052 & -0.004 & -0.005 \\
\hline STR2 & $\sigma_{2}^{-}$ & Fitting point 2 - Stress $\left[\mathrm{N} / \mathrm{mm}^{2}\right]$ & -2.30 & -3.6 & -1.40 & -4.0 \\
\hline
\end{tabular}


Table 4 Continuum damage model parameters - tensile branch.

Parameters

\begin{tabular}{llcccc}
\hline $\boldsymbol{G V A \boldsymbol { L }}$ & Tensile fracture energy $\left[\mathrm{J} / \mathrm{m}^{2}\right]$ & 50 & 50 & 50 & 50 \\
$\boldsymbol{F T U L}$ & Tensile stress $\left[\mathrm{N} / \mathrm{mm}^{2}\right]$ & 0.05 & 0.17 & 0.06 & 0.15 \\
$\boldsymbol{R E D C C}$ & Drop factor for peak tensile stress [-] & 0 & 0 & 0 & 0 \\
$\boldsymbol{N C R I}$ & Tensile softening criteria [-] & 1 & 1 & 1 & 1 \\
\hline
\end{tabular}


Table 5 Parameters for shear-compression tests.

\begin{tabular}{|c|c|c|c|c|}
\hline Parameters & $3 \mathrm{LF}_{\mathrm{NI}}$ & $3 \mathrm{LF}_{\mathrm{I}}$ & $3 \mathrm{LS}_{\mathrm{NI}}$ & $3 \mathrm{LS}_{\mathrm{I}}$ \\
\hline Elastic modulus $\left[\mathrm{N} / \mathrm{mm}^{2}\right]$ & $3.3 \cdot 10^{3}$ & $5.0 \cdot 10^{3}$ & $3.0 \cdot 10^{3}$ & $4.7 \cdot 10^{3}$ \\
\hline Poisson ratio [-] & 0.19 & 0.12 & 0.19 & 0.12 \\
\hline Density $\left[\mathrm{kg} / \mathrm{m}^{3}\right]$ & 2200 & 2500 & 2200 & 2500 \\
\hline Tensile fracture energy $\left[\mathrm{J} / \mathrm{m}^{2}\right]$ & 50 & 50 & 50 & 50 \\
\hline Tensile stress $\left[\mathrm{N} / \mathrm{mm}^{2}\right]$ & 0.05 & 0.17 & 0.06 & 0.15 \\
\hline Drop factor for peak tensile stress [-] & 0 & 0 & 0 & 0 \\
\hline Elastic limit compressive stress $\left[\mathrm{N} / \mathrm{mm}^{2}\right]$ & -0.85 & -1.5 & -0.5 & -1.5 \\
\hline Equi-biaxial Compressive Ratio [-] & 1 & 1 & 1 & 1 \\
\hline Compressive peak stress $\left[\mathrm{N} / \mathrm{mm}^{2}\right]$ & -2.6 & -6.5 & -3.5 & -6.6 \\
\hline Ultimate limit strain [-] & -0.02 & -0.025 & -0.02 & -0.025 \\
\hline Reference strain for plastic parameter [-] & -0.0009 & -0.0008 & -0.00075 & -0.0017 \\
\hline Reference stress for plastic parameter $\left[\mathrm{N} / \mathrm{mm}^{2}\right]$ & -1.5 & -2.8 & -1.45 & -3.9 \\
\hline Fitting point 1 - Strain [-] & -0.0009 & -0.0008 & -0.00075 & -0.0017 \\
\hline Fitting point $1-$ Stress $\left[\mathrm{N} / \mathrm{mm}^{2}\right]$ & -1.5 & -2.8 & -1.45 & -3.9 \\
\hline Fitting point 2 - Strain [-] & -0.01 & -0.016 & -0.021 & -0.023 \\
\hline Fitting point 2 - Stress $\left[\mathrm{N} / \mathrm{mm}^{2}\right]$ & -2.4 & -4.7 & -1.8 & -4.4 \\
\hline
\end{tabular}


Table 6 Variation of the parameter values.

\begin{tabular}{llcccc}
\multicolumn{1}{c}{ Parameters } & $3 \mathrm{LF}_{\mathrm{NI}}$ & $3 \mathrm{LF}_{\mathrm{I}}$ & $3 \mathrm{LS}_{\mathrm{NI}}$ & $3 \mathrm{LS}_{\mathrm{I}}$ \\
\hline \hline YOUN & Elastic modulus [\%] & 10 & -14 & 36 & -10 \\
$\boldsymbol{F C 0 1}$ & Elastic limit compressive stress [\%] & -8 & -26 & -66 & -25 \\
$\boldsymbol{F C U 1}$ & Compressive peak stress [\%] & 0 & 51 & 58 & 42 \\
$\boldsymbol{E X T U}$ & Ultimate limit strain [\%] & 300 & 339 & 388 & 400 \\
$\boldsymbol{E X T P}$ & Reference strain for plastic parameter [\%] & 0 & -60 & -38 & 42 \\
$\boldsymbol{S T R P}$ & Reference stress for plastic parameter [\%] & -17 & -24 & -24 & 8 \\
$\boldsymbol{E X T 1}$ & Fitting point 1 - Strain [\%] & 0 & -60 & -38 & 42 \\
$\boldsymbol{S T R 1}$ & Fitting point 1 - Stress [\%] & -17 & -24 & -24 & 8 \\
$\boldsymbol{E X T 2 ~}$ & Fitting point 2 - Strain [\%] & 100 & 208 & 425 & 360 \\
$\boldsymbol{S T R 2 ~}$ & Fitting point 2 - Stress [\%] & 4 & 31 & 29 & 10 \\
\hline
\end{tabular}


Table 7 Numerical and experimental maximum horizontal load $\left(\mathrm{H}_{\max }\right)$, displacement at maximum load $\left(\delta_{\mathrm{Hmax}}\right)$ and ultimate displacement $\left(\delta_{\mathrm{u}}\right)$.

\begin{tabular}{|c|c|c|c|c|c|c|c|c|c|}
\hline \multirow[b]{2}{*}{ Panels } & \multicolumn{3}{|c|}{ Experimental } & \multicolumn{3}{|c|}{ Numerical } & \multirow{2}{*}{$\begin{array}{c}H_{\max , n} / \\
H_{\max , e} \\
{[-]} \\
\end{array}$} & \multirow{2}{*}{$\begin{array}{c}\delta_{\text {Hmax }, n} / \\
\delta_{\text {Hmax }, e} \\
{[-]} \\
\end{array}$} & \multirow{2}{*}{$\begin{array}{c}\delta_{u, n} / \delta_{u, e} \\
{[-]}\end{array}$} \\
\hline & $\begin{array}{c}H_{\text {max }, e} \\
{[k N]} \\
\end{array}$ & $\begin{array}{c}\delta_{\text {Hmax }, e} \\
{[\mathrm{~mm}]} \\
\end{array}$ & $\begin{array}{c}\delta_{u, e} \\
{[m m]} \\
\end{array}$ & $\begin{array}{c}\boldsymbol{H}_{\max , n} \\
{[\mathrm{kN}]} \\
\end{array}$ & $\begin{array}{c}\delta_{H \max , n} \\
{[\mathrm{~mm}]} \\
\end{array}$ & $\begin{array}{c}\delta_{u, n} \\
{[m m]} \\
\end{array}$ & & & \\
\hline$S C 3 L F_{1.0 N I}$ & 116.3 & 4.0 & 6.7 & 114.0 & 4.0 & 5.0 & 0.98 & 1.0 & 0.75 \\
\hline$S C 3 L F_{1.25 N I}$ & 104.6 & 2.4 & 2.8 & 114.0 & 2.9 & 3.2 & 1.1 & 1.2 & 1.1 \\
\hline$S C 3 L F_{0.75 N I}$ & 77.0 & 2.5 & 4.3 & 99.6 & 4.0 & 4.5 & 1.3 & 1.6 & 1.1 \\
\hline$S C 3 L F_{0.5 N I}$ & 76.0 & 6.4 & 10.3 & 80.0 & 5.0 & 9.0 & 1.1 & 0.78 & 0.87 \\
\hline \multicolumn{7}{|c|}{ Average } & 1.1 & 1.15 & 0.96 \\
\hline$S C 3 L F_{1.0 I}$ & 172.2 & 19.9 & 21.6 & 160.8 & 7.0 & 9.0 & 0.93 & 0.35 & 0.42 \\
\hline$S C 3 L F_{1.5 I}$ & 215.0 & 5.3 & 6.5 & 211.0 & 5.0 & 7.0 & 0.98 & 0.94 & 1.1 \\
\hline$S C 3 L F_{1.25 I}$ & 208.2 & 15.0 & 18.1 & 193.0 & 6.3 & 7.0 & 0.93 & 0.42 & 0.39 \\
\hline$S C 3 L F_{2.0 I}$ & 258.7 & 6.1 & 7.8 & 255.0 & 5.5 & 6.0 & 0.99 & 0.90 & 0.77 \\
\hline \multicolumn{7}{|c|}{ Average } & 0.96 & 0.50 & 0.67 \\
\hline$S C 3 L S_{1.0 N I}$ & 67.6 & 5.1 & 6.7 & 67.8 & 5.0 & 5.4 & 1.0 & 0.98 & 0.81 \\
\hline$S C 3 L S_{0.75 N I}$ & 53.4 & 4.9 & 6.8 & 56.8 & 5.5 & 6.5 & 1.1 & 1.1 & 0.96 \\
\hline$S C 3 L S_{1.25 N I}$ & 73.3 & 3.6 & 6.2 & 75.3 & 4.5 & 4.9 & 1.0 & 1.3 & 0.79 \\
\hline \multicolumn{7}{|c|}{ Average } & 1.0 & 1.1 & 0.85 \\
\hline$S C 3 L S_{I .25 I}$ & 102.5 & 9.0 & 14.1 & 94.9 & 7.5 & 9.0 & 0.93 & 0.83 & 0.64 \\
\hline$S C 3 L S_{1.0 I}$ & 89.4 & 16.3 & 19.1 & 81.0 & 7.0 & 9.0 & 0.91 & 0.43 & 0.47 \\
\hline$S C 3 L S_{1.5 I}$ & 103.3 & 5.7 & 8.9 & 107 & 6.5 & 8.5 & 1.0 & 1.1 & 0.96 \\
\hline$S C 3 L S_{2.0 I}$ & 116.8 & 4.9 & 6.1 & 127 & 5.0 & 6.0 & 1.1 & 1.0 & 0.98 \\
\hline \multicolumn{7}{|c|}{ Average } & 0.99 & 0.84 & 0.76 \\
\hline
\end{tabular}

